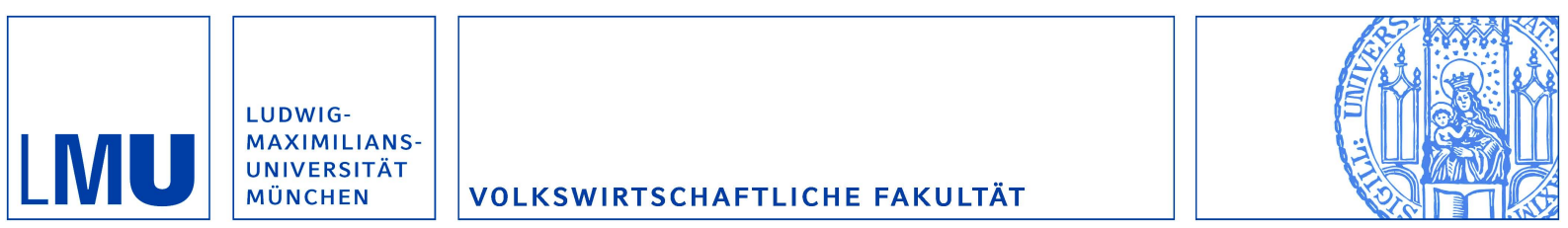

Herweg, Fabian und Müller, Daniel:

Price Discrimination in Input Markets: Quantity Discounts and Private Information

Munich Discussion Paper No. 201 1-18

Department of Economics

University of Munich

Volkswirtschaftliche Fakultät

Ludwig-Maximilians-Universitäł München

Online at https://doi.org/10.5282/ubm/epub. 12414 


\title{
Price Discrimination in Input Markets: Quantity Discounts and Private Information*
}

\author{
FABIAN HERWEG ${ }^{\dagger}$ AND DANIEL MÜLLER ${ }^{\ddagger}$
}

November 8, 2011

\begin{abstract}
We consider a monopolistic supplier's optimal choice of wholesale tariffs when downstream firms are privately informed about their retail costs. Under discriminatory pricing, downstream firms that differ in their ex ante distribution of retail costs are offered different tariffs. Under uniform pricing, the same wholesale tariff is offered to all downstream firms. In contrast to the extant literature on thirddegree price discrimination with nonlinear wholesale tariffs, we find that banning discriminatory wholesale contracts-the usual legal practice in the EU and USoften is beneficial for social welfare. This result is shown to be robust even when the upstream supplier faces competition in the form of fringe supply.
\end{abstract}

\section{JEL classification: D43; L11; L42}

Keywords: Asymmetric Information; Input Markets; Quantity Discounts; Price Discrimination; Screening; Vertical Contracting

\section{INTRODUCTION}

Third-degree price discrimination is a widely used business practice in intermediate-good markets, i.e., manufactures often apply different conditions to identical transactions with different retailers. The pros and cons of this pricing practice have been discussed among legal and economic scholars since the 30's and are still debatable. Whether third-degree price discrimination by a large manufacturer represents an abuse of its dominant position is a crucial question in many antitrust decisions on both sides of the Atlantic ocean. ${ }^{1}$ For a long time, the economic literature on third-degree price discrimination has presumed that it is optimal for the manufacturer to offer linear wholesale contracts. As documented by recent empirical evidence, however, another common pricing practice employed by manufacturers are quantity rebate schemes ${ }^{2}-$ which is hardly surprising in the face of the well-known double marginalization problem. In the

\footnotetext{
${ }^{*}$ We have benefited from comments made by conference audiences at EARIE (Stockholm), the SFB Meeting (Tutzing), and the ANR-DFG Workshop on Market Power in Vertically Related Markets (Paris) as well as seminar audiences at the University of Toulouse, and by Frago Kourandi, Matthias Kräkel, Takeshi Murooka, Claudia Salim, Klaus M. Schmidt and Patrick Schmitz. All errors are of course our own.

${ }^{\dagger}$ University of Munich, Department of Economics, Ludwigstr. 28, D-80539 Munich, Germany, E-mail address: fabian.herweg@1rz.uni-muenchen.de

${ }^{\ddagger}$ University of Bonn, Department of Economics, Adenauerallee 24-42, D-53113 Bonn, Germany, E-mail address: daniel.mueller@uni-bonn.de, Tel: +49-228-733918, Fax: +49-228-739210 (corresponding author).

${ }^{1}$ For an overview of landmark antitrust cases in the EU see Russo et al. (2010).

${ }^{2}$ Analyzing data obtained from the American yogurt market and the French market for bottled mineral water, respectively, Villas-Boas (2007) and Bonnet and Dubois (2010) find that vertical contracts between manufacturers and retailers are often nonlinear.
} 
light of such evidence, there has been renewed interest in exploring the implications of banning third-degree price discrimination in input markets when wholesale contracts allow for quantity discounts. By and large, the emerging literature on third-degree price discrimination in input markets under nonlinear wholesale contracts agrees upon a ban on price discrimination being detrimental for social welfare—see O'Brien and Shaffer (1994), Rey and Tirole (2007), Inderst and Shaffer (2009), and Arya and Mittendorf (2010).

This clearcut theoretical prediction is at odds with the legal practice in the EU as well as in the US, where antitrust authorities regard quantity discounts as a justifiable pricing strategy of manufacturers as long as they are non-discriminatory. This point of view of antitrust authorities, e.g. the European Commission, becomes apparent, in a series of decisions. For instance, in the Michelin I judgment from 1981; the Commission did not contest the quantity rebate scheme itself, but its alleged discriminatory nature with "comparable amounts purchased almost never result[ing] in the same or comparable discount being granted." (Recital 42 of Commission decision 81/969/EEC) Likewise, in the European sugar industry decision from 1973, the Commission ruled that "the granting of a rebate which does not depend on the amount bought [...] is an unjustifiable discrimination [...]." (Recital II-E-1 of Commission decision 73/109/EC) ${ }^{3}$ In contrast to the extant theoretical literature, but in line with the usual legal practice, we derive conditions such that banning discriminatory nonlinear wholesale contracts is socially desirable. The novelty of our paper is to allow for privately informed downstream firms, a possibility which so far has been ignored in the literature.

We investigate the welfare effects of banning discriminatory nonlinear wholesale tariffs in a model with two downstream firms that have private information regarding their own retail cost, which is either high or low. Ex ante, downstream firms differ in the distribution of their retail cost and this is known by a monopolistic upstream manufacturer. If third-degree price discrimination is permitted, the manufacturer offers to downstream firms with different distributions of retail costs a different menu of transfer-quantity pairs. Under uniform pricing, on the other hand, the same menu is offered to both downstream firms. When deciding whether to accept the manufacturer's offer, each downstream firm is privately informed about the realization of its retail cost. Thus, the manufacturer does not only offer nonlinear tariffs to reduce double marginalization but also to screen downstream firms according to retail efficiency. ${ }^{4}$

In our baseline model, the two downstream firms serve independent markets which allows us to disentangle the effect of banning discriminatory wholesale tariffs from potential competitive effects. Moreover, with the European Commission taking a strict stand against geographic price discrimination across countries, the case of separate markets seems a natural starting point for our analysis. ${ }^{5}$ Here, the quantities produced by low-cost retailers are independent of the pricing

\footnotetext{
${ }^{3}$ Other decisions include the Eurofix-Bauco/Hilti case, where the commission objected that the reduction of discounts was not linked primarily to any objective criteria such as quantity. (Commission decision 88/138/EEC) Even in the Michelin II judgment from 2003, which sometimes is seen as a per se rule against rebates (Waelbroeck, 2005), the Commission stated that "the Court of Justice has ruled against the granting of quantity rebates by an undertaking in a dominant position where the rebates exceed a reasonable period of three months [...] on the grounds that such a practice is not in line with normal competition based on price." (Recital 216 of Commission decision 2002/405/EC) Thus, it was not the quantity rebate per se, but rather the reference period of one year that was contested by the Commission.

${ }^{4} \mathrm{~A}$ model of vertical relations where downstream firms' costs are stochastic is analyzed by Rey and Tirole (1986). They do not discuss third-degree price discrimination.

${ }^{5}$ For geographic price discrimination to be feasible, parallel imports-i.e., arbitraging across countries-have to be absent. As stated in the 29th Report on Competition Policy, "the Commission has used its competition policy
} 
regime because under both regimes there is no-distortion-at-the-top. The quantities procured by high-cost retailers, on the other hand, depend on the pricing regime. Under price discrimination, the high-cost type of the ex ante more efficient firm-more likely to be a low cost producer-procures a lower quantity than the high-cost type of the ex ante less efficient firm. The quantity procured by ex post high-cost retailers under uniform pricing is bracketed by the quantities assigned to high-cost retailers under price discrimination. Banning price discrimination therefore-in expectations - harms the market which is served by the ex ante more efficient firm, whereas the other market, which is served by the ex ante less efficient firm, benefits. Due to these opposing effects, general welfare results are hard to obtain. Nevertheless, we show that uniform pricing is optimal from a welfare point of view as long as price discrimination does not lead to an expansion of (expected) total output. For the case of linear demand and provided that all markets are being served under either pricing regime, price discrimination does not lead to an expansion of total output and thus is detrimental for welfare.

The manufacturer, however, might consider it optimal not to serve a high-cost retailer. On the one hand, if the ex ante more efficient firm is very unlikely to produce at high cost but the average probability of high-cost production nevertheless is quite high, then the high-cost type of the ex ante more efficient firm is served under uniform pricing but not under price discriminationi.e., uniform pricing leads to more markets being served in expectations. In this case, with price discrimination benefiting one market (due to a lower quantity distortion) but harming the other market (which may not be served), again a ban on price discrimination improves welfare if price discrimination does not lead to an expansion of (expected) total output. On the other hand, if the average probability of high-cost production is low but the ex ante less efficient firm is nevertheless quite likely to produce at high cost, then only under price discrimination - and only in the ex ante less efficient market-high-cost production takes place. Here, price discrimination leads to more markets being served in expectations and unambiguously improves welfare. This finding resembles the classic Chicago school argument in favor of price discrimination (see Bork, 1978).

Next to the static setting we analyze a dynamic model in order to investigate the long-run effects of banning discriminatory wholesale contracts. Extending our model to a long-run analysis in the spirit of DeGraba (1990), we identify another channel through which uniform pricing can improve welfare: if downstream firms are allowed to invest into the (expected) efficiency in production, uniform pricing results in higher investment incentives, thereby potentially leading to overall higher welfare. This conjecture is confirmed for the case of linear demand downstream.

We demonstrate robustness of our main result - that is, a ban on price discrimination being welfare improving even when nonlinear wholesale contracts are feasible-in several directions. Most importantly, we introduce competition between intermediate firms in our static setting in order to allow for the possibility of a secondary line injury, i.e., one downstream firm being placed at a competitive disadvantage. Given that competition is not too tough, banning price discrimination is socially desirable. Moreover, in order to allow for the manufacturer's pricing behavior also causing primary-line injuries in the upstream market, we augment the basic model by assuming that downstream firms can purchase the essential input not only from the manu-

as an active tool [for] [...] prohibiting, and fining heavily the parties to [...] agreements that prevent parallel trade between member states". 
facturer but also from a competitive fringe. Most of our findings are robust toward this kind of upstream competition. In particular, for linear demand, a ban on discriminatory wholesale tariffs improves welfare for a wide range of parameter values.

The rest of the paper is organized as follows: Section 2 reviews the related literature. In Section 3, we introduce our basic model with a monopolistic input supplier and downstream firms operating in separate markets. This model is analyzed in Section 4. In Section 5, we extend the basic model to a long-run analysis by allowing for downstream firms to invest in reduction of production cost before contracting takes place. After allowing for a continuous type distribution for downstream firms in Section 6, we discuss in Section 7 to what extent our findings carry over the case of downstream competition. Section 8 augments the basic model by assuming that the upstream supplier is constrained by the threat of demand-side substitution. We conclude in Section 9. All proofs are relegated to the Appendix.

\section{RELATED Literature}

There has been considerable back and forth in the literature regarding the welfare effects of banning third-degree price discrimination in intermediate-good markets. This literature was initiated by Katz (1987), who shows that price discrimination reduces welfare unless it prevents inefficient backward integration by the downstream chain. DeGraba (1990) extends Katz's model to a long-run analysis where downstream firms can invest into cost reduction. Here, price discrimination does not only decrease welfare in the short run, but also is detrimental in the long run. The intuition behind these results is that the "wrong" firm — the less efficient one-receives a discount under price discrimination. ${ }^{6}$ While the above articles assume that the manufacturer is an unconstrained monopolist, Inderst and Valletti (2009) and O'Brien (forthcoming) relax this assumption. In Inderst and Valletti the manufacturer is constrained by the threat of demand-side substitution. Here, the more efficient firm receives a discount under price discrimination. As a result—in the long run—consumers benefit and social surplus increases if price discrimination is permitted and demand is linear. O'Brien assumes that wholesale prices are determined by bilateral negotiations between the manufacturer and downstream firms. This also gives rise to circumstances where price discrimination is socially desirable. ${ }^{7}$

All the aforementioned articles restrict attention to linear wholesale prices. Thus, with linear wholesale tariffs the welfare results regarding a ban on price discrimination are mixed. Among the few exceptions which consider pricing schemes more complex than linear wholesale prices, in contrast, the predominant opinion is that banning discriminatory wholesale pricing is detrimental for welfare. O'Brien and Shaffer (1994) assume that firms can bargain over the terms of a two-part supply tariff. Banning price discrimination renders retailer bargaining power useless and restores the manufacturer's market power, resulting in higher marginal input prices for all downstream firms under uniform pricing than under price discrimination. Thus, a ban on price discrimination is harmful for consumers and reduces total welfare. A similar model is analyzed by Rey and Tirole (2007). Here, with the manufacturer having all the bargaining power, "non-

\footnotetext{
${ }^{6}$ Similar results are obtained by Yoshida (2000) and Valletti (2003).

${ }^{7}$ Mixed welfare results regarding price discrimination in input markets are also obtained by Herweg and Müller (forthcoming), who allow for endogenous determination of the structure of the downstream industry.
} 
discrimination laws [...] reduce consumer surplus and total welfare by enabling the monopolist to commit" (p.32). ${ }^{8}$ Inderst and Shaffer (2009) abstract from any commitment problems and assume that the offered two-part tariffs are publicly observable. Focusing on asymmetric downstream firms, discriminatory contracts are shown to amplify differences in downstream firms' competitiveness. Again, a ban on price discrimination tends to raise all final-good prices and thus to reduce total output. In consequence, banning price discrimination reduces consumer surplus and total welfare. Lastly, Arya and Mittendorf (2010) show a ban on discriminatory two-part tariffs to be always welfare harming when downstream firms operate in multiple product markets. Thus, while the above "insight raises [...] serious concerns about the efficacy of the Robinson-Patman Act" (O'Brien and Schaffer, 1994, p.314) or its analogue in EU competition law, we find that, when downstream firms have private information, the reservation toward discriminatory pricing practices embodied in these legal enactments may well be warranted even if nonlinear pricing schemes are feasible.

Considering a model with network effects and inelastic demand, Giardino-Karlinger and Motta (forthcoming) find that third-degree price discrimination can be welfare harming if wholesale tariffs more copmlex than linear pricing are considered. In our model there are no network effects and demand is elastic, which implies that double marginalization is an issue.

\section{THE MODEL}

Consider a vertically related industry where the upstream market is monopolized by manufacturer $M$. The manufacturer produces an essential input that is supplied to the downstream sector. For simplicity, we assume that the manufacturer produces quantity $q$ at constant marginal cost, $K>0$. There are two downstream firms, $i \in\{1,2\}$, that can transform one unit of the input into one unit of the final good.

We assume that downstream firms operate in distinct and independent markets, i.e., each downstream firm is a local monopolist-we comment on this assumption below and relax it in a later section.. Downstream markets are identical in size and characterized by the inverse demand function $P(q)$, which is strictly decreasing, twice differentiable where $P>0$, and satisfies the standard assumption $P^{\prime}(q)<\min \left\{0,-q P^{\prime \prime}(q)\right\}$ where $P>0 .{ }^{9}$

Downstream firm $i$ produces at constant marginal cost and without fixed costs. The marginal cost of production is either high or low, $c_{i} \in\left\{c_{L}, c_{H}\right\}$ with $0 \leq c_{L}<c_{H}<P(0)-K$. The last inequality guarantees that the joint-surplus maximizing quantity of a vertically integrated firm is strictly positive.

Let $\alpha_{i}$ denote the probability that firm $i$ produces at low marginal cost. Ex ante firm 1 is more likely to produce at low marginal cost than firm 2, i.e., $0<\alpha_{2}<\alpha_{1}<1$. Its type-i.e., its marginal cost of production-is private information of the respective downstream firm. The manufacturer only knows the probability $\alpha_{i}, i \in\{1,2\}$, with which downstream firm $i$ is the low-cost type.

\footnotetext{
${ }^{8}$ Building on the Rey-Tirole model and assuming that the manufacturer competes against a competitive fringe, Caprice (2006) shows that a ban on price discrimination leads to an increase in welfare if the fringe is sufficiently efficient.

${ }^{9}$ See, for example, Vives (1999).
} 
The manufacturer can make a take-it-or-leave-it offer to the downstream firms. ${ }^{10}$ With downstream firms operating in independent markets and with the type space being identical for both downstream firms, without loss of generality, the manufacturer offers downstream firm $i \in\{1,2\}$ a direct mechanism $\Gamma_{i}=\left\langle\left(q_{L i}, t_{L i}\right),\left(q_{H i}, t_{H i}\right)\right\rangle$, that specifies a quantity, $q \in \mathbb{R}_{\geq 0}$, and a transfer from firm $i$ to the manufacturer, $t \in \mathbb{R}$, for each feasible type announcement.

With this type of wholesale contracts, the question whether or not a downstream firm is forced to sell the whole quantity procured is immediately at hand. We assume free disposal for downstream firms: when having purchased quantity $q^{\prime}$ of the input, downstream firm $i$ can produce any quantity $q \in\left[0, q^{\prime}\right]$ of the final output at cost $c_{i} q$.

The sequence of events is as follows: first, nature draws the cost type for each downstream firm $i \in\{1,2\}$, which thereafter is privately observed. Next, the manufacturer makes a take-itor-leave-it offer to each downstream firm. Under price discrimination the manufacturer offers each downstream firm a possibly different tariff, whereas under uniform pricing one and the same tariff applies to both firms. ${ }^{11}$ A downstream firm either chooses one of the two offered bundles or it rejects the manufacturer's offer. In case of rejection, the downstream firm obtains its reservation profit, which is normalized to zero. If the downstream firm accepts a quantitytransfer pair $(q, t)$, it decides how much of this acquired input to transform into the final good, and sells the produced output to consumers.

We focus on separate markets in order to isolate the effect of discriminatory wholesale tariffs in the case of asymmetric information from potential competitive effects. From an applied point of view, this restriction also seems justifiable: besides geographic price discrimination, a case in which separate markets are a natural assumption, jurisdictions on both sides of the Atlantic ocean are mostly concerned with whether discriminatory pricing causes a primary-line or secondary-line injury. Since the comprehensive renumeration of articles by the Treaty of Lisbon, primary-line and secondary-line injury are addressed in Article 102(b) and (c) ECformerly Article 82(b) and (c) - respectively. ${ }^{12}$ Article 102(b) does not impose the requirement that a downstream firm has to be placed at a competitive disadvantage in the first place. Application of Article 102(c), on the other hand, calls for a downstream firm to be placed at a disadvantageous position, but recent practice of the EU Commission generally overlooked this requirement when relying on Article 102(c). ${ }^{13}$ Likewise, the Robinson-Patman Act in US competition law requires a substantial injury to competition for price discrimination to be deemed illegal. According to the usually applied Morton Salt rule, however, the standard of proof for competitive harm in a secondary-line case is rather low-existence of a substantial price differ-

\footnotetext{
${ }^{10}$ The assumption of the manufacturer having all the bargaining power, "which arguably can be justified on the grounds that for antitrust purposes the considerations of price discrimination in intermediate-goods markets is primarily relevant if the supplier enjoys a dominant position" (Inderst and Shaffer (2009), p.4) is common in the extant literature. The only exceptions are O'Brien and Shaffer (1994) and O'Brien (2008).

${ }^{11}$ As noted by Inderst and Shaffer (2009), another way to model uniform pricing would be to assume that the manufacturer can offer a menu of tariffs, as long as the same menu is offered to both downstream firms. In our setup the manufacturer cannot benefit from offering a menu of nonlinear tariffs, since downstream firms cannot be screened according to their ex ante efficiency.

${ }^{12}$ While the first type of price discrimination involves discrimination on the part of a dominant firm with the objective of excluding rival competitors, the latter type refers to the charging of different prices to downstream competitors thereby placing one or more of them at a competitive disadvantage relative to others.

${ }^{13}$ As criticized by, for example, Geradin and Petit (2005), when dealing with cases involving primary-line injury price discrimination, the EU Commission often relies on Article 102(c) EC-instead of Article 102(b) EC-and usually tends to ignore the requirement that the pricing practice in question has to put one downstream firm at a competitive disadvantage.
} 
ence for a substantial period of time is sufficient. (FTC v. Morton Salt Co., 334 U.S. 37$)^{14}$

\section{The ANALysis}

Let $q^{*}(c)=\arg \max _{q \geq 0}\{(P(q)-c) q\}$ denote the quantity optimally produced by a downstream firm that operates at marginal cost $c$. It is readily verified that $q^{*}(\cdot)$ is strictly decreasing in $c$, such that $q^{*}\left(c_{H}\right)<q^{*}\left(c_{L}\right)$. Due to free disposal, downstream firm $i$ 's maximum profit when faced with tupel $(q, t)$ is $\pi\left(q, c_{i}\right)-t$, where

$$
\pi\left(q, c_{i}\right)=\left[P\left(\min \left\{q, q^{*}\left(c_{i}\right)\right\}\right)-c_{i}\right] \min \left\{q, q^{*}\left(c_{i}\right)\right\} .
$$

Thus, downstream firm $i$ 's gross profits $\pi\left(q, c_{i}\right)$ are strictly increasing and strictly concave in $q$ on $\left[0, q^{*}\left(c_{i}\right)\right)$ and constant for $q \geq q^{*}\left(c_{i}\right)$. Moreover, a low-cost downstream firm benefits more from an increase in the quantity of the input than a high-cost downstream firm. That is, formally $\pi\left(q, c_{i}\right)$ satisfies the following single-crossing property:

Lemma 1 For all $0 \leq q^{\prime}<q^{\prime \prime} \leq q^{*}\left(c_{L}\right), \pi\left(q^{\prime \prime}, c_{L}\right)-\pi\left(q^{\prime}, c_{L}\right)>\pi\left(q^{\prime \prime}, c_{H}\right)-\pi\left(q^{\prime}, c_{H}\right)$.

Let $q^{J S}(c)=\arg \max _{q \geq 0}(P(q)-c) q-K q$ denote the optimal quantity produced by a vertically integrated structure comprising of the manufacturer and a downstream firm with marginal cost $c$. Under the imposed assumptions we have $0<q^{J S}(c)<q^{*}(c)$. Since $q^{J S}(\cdot)$ is strictly decreasing in marginal cost $c$, it holds that

$$
q^{J S}\left(c_{H}\right)<\min \left\{q^{*}\left(c_{H}\right), q^{J S}\left(c_{L}\right)\right\} \leq \max \left\{q^{*}\left(c_{H}\right), q^{J S}\left(c_{L}\right)\right\}<q^{*}\left(c_{L}\right) .
$$

\subsection{Discriminatory Offers}

Suppose $M$ is not restricted to offering the same wholesale tariffs to both downstream firms. Since downstream firms operate in independent markets, $M$ solves two independent maximization problems. Thus, when contracting with a downstream firm that produces at low costs with probability $\alpha, M$ offers this firm a wholesale mechanism $\Gamma=\left\langle\left(q_{L}, t_{L}\right),\left(q_{H}, t_{H}\right)\right\rangle$ that maximizes expected upstream profits,

$$
\Pi^{D}\left(q_{L}, q_{H}, t_{L}, t_{H}\right)=\alpha\left[t_{L}-K q_{L}\right]+(1-\alpha)\left[t_{H}-K q_{H}\right] .
$$

subject to the constraints that $\Gamma$ is truthful and individually rational.

The wholesale mechanism is truthful if and only if it satisfies the incentive compatibility constraints for both cost types, i.e., each cost type has to prefer its own designated bundle over the bundle designated to the other type. Formally,

$$
\begin{gathered}
\pi\left(q_{L}, c_{L}\right)-t_{L} \geq \pi\left(q_{H}, c_{L}\right)-t_{H}, \\
\pi\left(q_{H}, c_{H}\right)-t_{H} \geq \pi\left(q_{L}, c_{H}\right)-t_{L} .
\end{gathered}
$$

\footnotetext{
${ }^{14}$ Only in the recent Volvo case, the Supreme Court for the first time required actual proof of retailers competing for the same customers in order to establish competitive harm compatible with the Morton Salt rule, thereby overruling the decision of a lower court. (Volvo Trucks North America, Inc. v. Reeder-Simco GMC, Inc. (04-905), 546 U.S. 164, 2006). For a more elaborate discussion of this point see Luchs et al. (2010).
} 
Moreover, the mechanism has two satisfy the individual rationality constraints, i.e., for each cost type the designated quantity transfer tuple has to yield nonnegative profits:

$$
\begin{array}{rrr}
\pi\left(q_{L}, c_{L}\right)-t_{L} \geq 0, & \left(\mathrm{IR}_{L}\right) \\
\pi\left(q_{H}, c_{H}\right)-t_{H} \geq 0 . & \left(\mathrm{IR}_{H}\right)
\end{array}
$$

Implications of free disposal.-An important implication of free disposal is that in the optimum we must have $q_{H} \leq q^{*}\left(c_{H}\right)$. To see this, assume the opposite, i.e., the optimal contract stipulates $q_{H}^{\prime}>q^{*}\left(c_{H}\right)$. Then, leaving $q_{L}$ and transfers $t_{L}$ and $t_{H}$ unchanged, $M$ could offer the high-cost type the lower quantity $q^{*}\left(c_{H}\right)$. First, this change obviously does not affect $\left(\operatorname{IR}_{L}\right)$. Moreover, due to free disposal, we have $\pi\left(q_{H}^{\prime}, c_{H}\right)=\pi\left(q^{*}\left(c_{H}\right), c_{H}\right)$, which implies that $\left(\operatorname{IR}_{H}\right)$ and $\left(\mathrm{IC}_{H}\right)$ are also left unchanged. Last, this decrease in the quantity offered to the high-cost type strictly relaxes $\left(\mathrm{IC}_{L}\right)$ because $\pi\left(q^{*}\left(c_{H}\right), c_{L}\right)<\pi\left(q_{H}^{\prime}, c_{L}\right)$. Thus, all constraints remain satisfied under this new contract, but upstream cost of production is strictly lower than under the original contract, contradicting its optimality. Analogous reasoning reveals that in the optimum we have $q_{L} \leq q^{*}\left(c_{L}\right)$.

Implications of incentive compatibility.-Combining and rearranging both incentive compatibility constraints, $\left(\mathrm{IC}_{L}\right)$ and $\left(\mathrm{IC}_{H}\right)$, yields

$$
\pi\left(q_{L}, c_{L}\right)-\pi\left(q_{H}, c_{L}\right) \geq t_{L}-t_{H} \geq \pi\left(q_{L}, c_{H}\right)-\pi\left(q_{H}, c_{H}\right) .
$$

As usual, incentive compatibility imposes the following monotonicity requirement: in the optimal contract we must have $q_{H} \leq q_{L}$. It follows that $\pi\left(q_{L}, c_{H}\right) \geq \pi\left(q_{H}, c_{H}\right)$, which in turn implies that $t_{L}-t_{H} \geq 0$.

The implications of free disposal and incentive compatibility are summarized in the following lemma:

Lemma 2 The optimal contract satisfies the following monotonicity constraint:

$$
q_{H} \leq \min \left\{q_{L}, q^{*}\left(c_{H}\right)\right\} \leq \max \left\{q_{L}, q^{*}\left(c_{H}\right)\right\} \leq q^{*}\left(c_{L}\right) .
$$

If $\left(\mathrm{IR}_{H}\right)$ and $\left(\mathrm{IC}_{L}\right)$ are satisfied, then $\left(\mathrm{IR}_{L}\right)$ also holds. Since the incentive compatibility constraints limit only the differences in transfers and not the absolute values, we can conclude that $\left(\mathrm{IR}_{H}\right)$ is binding at the optimum. The remaining incentive compatibility constraint, $\left(\mathrm{IC}_{H}\right)$, then holds as long as the monotonicity requirement $q_{H} \leq q_{L}$ is met.

Hence, the transfers $t_{H}$ and $t_{L}$ are uniquely determined by $\left(\mathrm{IR}_{H}\right)$ and $\left(\mathrm{IC}_{L}\right)$,

$$
\begin{aligned}
t_{H} & =\pi\left(q_{H}, c_{H}\right), \\
t_{L} & =\pi\left(q_{L}, c_{L}\right)-\pi\left(q_{H}, c_{L}\right)+\pi\left(q_{H}, c_{H}\right) .
\end{aligned}
$$

The manufacturer's problem consists of choosing quantities $q_{L}$ and $q_{H}$ to maximize upstream profits under a discriminatory pricing regime,

$$
\begin{aligned}
\Pi^{D}\left(q_{L}, q_{H}\right)=\alpha\left\{\left[P\left(q_{L}\right)-c_{L}\right] q_{L}-q_{H}\left(c_{H}-c_{L}\right)-K q_{L}\right\} & \\
& +(1-\alpha)\left\{\left[P\left(q_{H}\right)-c_{H}\right] q_{H}-K q_{H}\right\}
\end{aligned}
$$


subject to the monotonicity requirement (MON). Setting the partial derivative of $\Pi^{D}(\cdot)$ with respect to $q_{L}$ equal to zero yields

$$
q_{L}^{D}=q^{J S}\left(c_{L}\right) .
$$

This is the well-known no-distortion-at-the-top result: the low-cost type produces the quantity that maximizes the joint surplus of the integrated structure.

The quantity sold to a high-cost downstream firm is distorted downwards in order to cut back on the information rent paid to a low-cost firm. The magnitude of the downward distortion depends on the probability with which $M$ deals with a low-cost downstream firm. If it is sufficiently unlikely that the downstream firm produces at high cost, then $M$ will offer the high-cost type a quantity equal to zero. Formally, due to strict concavity of upstream revenues with respect to $q_{H}$ as long as $P(q)>0, M$ will offer the high-cost type a quantity equal to zero if and only if

$$
\left.\frac{\partial \Pi^{D}}{\partial q_{H}}\right|_{q_{H}=0} \leq 0 \Longleftrightarrow \alpha \geq \hat{\alpha}:=\frac{P(0)-c_{H}-K}{P(0)-c_{L}-K} .
$$

For $\alpha<\hat{\alpha}$, on the other hand, the optimal quantity sold to the high-cost type, $\hat{q}^{D}(\alpha)$, is strictly positive and satisfies the following first-order condition:

$$
P\left(\hat{q}^{D}(\alpha)\right)-c_{H}+P^{\prime}\left(\hat{q}^{D}(\alpha)\right) \hat{q}^{D}(\alpha)=K+\frac{\alpha}{1-\alpha}\left(c_{H}-c_{L}\right) .
$$

Obviously, $\hat{q}^{D}(\alpha)$ is strictly decreasing in $\alpha$ and $\lim _{\alpha \searrow 0} \hat{q}^{D}(\alpha)=q^{J S}\left(c_{H}\right)$. Intuitively, as the probability of dealing with a low-cost downstream firm becomes smaller, $M$ chooses the quantity offered to the high-cost type closer to the joint-surplus maximizing quantity $q^{J S}\left(c_{H}\right)$. If, on the other hand, the probability of contracting with a low-cost downstream firm is sufficiently high, then $M$ prefers to offer a zero quantity to the high-cost type, which eliminates information rents and in turn allows $M$ to extract all the surplus from the interaction with a low-cost type. Note that the quantities $\hat{q}^{D}(\alpha)$ and $q_{L}^{D}$ satisfy the monotonicity constraint (MON).

Proposition 1 Under discriminatory wholesale tariffs, (i) $q_{L}^{D}=q^{J S}\left(c_{L}\right)$ and (ii) $q_{H}^{D}(\alpha)=$ $\hat{q}^{D}(\alpha)$ if $\alpha<\hat{\alpha}$ and zero otherwise.

It is worthwhile to point out that $\hat{\alpha}$ approaches 1 as $c_{H}-c_{L}$ tends to zero. Put verbally, if the difference in possible retail costs is not too high, then both cost types are very likely to be served by the manufacturer.

\subsection{Uniform Pricing}

Suppose third-degree price discrimination in the intermediate good market is banned. In this case, $M$ has to offer the same menu to both downstream firms, i.e., $\Gamma_{1}=\Gamma_{2}$. Since this restriction leaves the set of incentive compatibility and individual rationality constraints unchanged, all the above considerations_Lemma 2 in particular-also apply in this situation. Therefore, $M$ chooses quantities $q_{L}$ and $q_{H}$ in order to maximize upstream profits,

$$
\begin{aligned}
\Pi^{U}\left(q_{L}, q_{H}\right)=\alpha_{\Sigma}\left\{\left[P\left(q_{L}\right)-c_{L}\right] q_{L}-q_{H}\left(c_{H}-c_{L}\right)-K q_{L}\right\} \\
+\left(2-\alpha_{\Sigma}\right)\left\{\left[P\left(q_{H}\right)-c_{H}\right] q_{H}-K q_{H}\right\},
\end{aligned}
$$


where $\alpha_{\Sigma}:=\alpha_{1}+\alpha_{2}$. Though imprecise, we will refer to $\alpha_{\Sigma}$ as the overall probability of contracting with a low-cost downstream firm. Differentiation of $\Pi^{U}(\cdot)$ with respect to $q_{L}$ reveals that the no-distortion-at-the-top result carries over to a nondiscriminatory pricing regime,

$$
q_{L}^{U}=q^{J S}\left(c_{L}\right)
$$

Analogous reasoning to the discriminatory pricing regime reveals that the quantity offered to the high-cost type decreases in the "average probability" of contracting with a low-cost downstream firm, $\alpha_{\Sigma} / 2$. Once this probability exceeds the threshold $\hat{\alpha}, M$ prefers not to serve the high-cost type. Formally, $M$ offers a zero quantity to high-cost downstream firms if and only if

$$
\left.\frac{\partial \Pi^{U}}{\partial q_{H}}\right|_{q_{H}=0} \leq 0 \Longleftrightarrow \frac{\alpha_{\Sigma}}{2} \geq \hat{\alpha} .
$$

For $\alpha_{\Sigma} / 2<\hat{\alpha}$, the quantity offered to high-cost types, $\hat{q}^{U}\left(\alpha_{\Sigma}\right)$, satisfies

$$
P\left(\hat{q}^{U}\left(\alpha_{\Sigma}\right)\right)-c_{H}+P^{\prime}\left(\hat{q}^{U}\left(\alpha_{\Sigma}\right)\right) \hat{q}^{U}\left(\alpha_{\Sigma}\right)=K+\frac{\alpha_{\Sigma} / 2}{1-\alpha_{\Sigma} / 2}\left(c_{H}-c_{L}\right) .
$$

Note that $\hat{q}^{U}\left(\alpha_{\Sigma}\right)$ is strictly decreasing in $\alpha_{\Sigma}$ and $\lim _{\alpha_{\Sigma} \searrow 0} \hat{q}^{U}\left(\alpha_{\Sigma}\right)=q^{J S}\left(c_{H}\right)$. Thus, (MON) is satisfied. In order to summarize the above observations, let

$$
\hat{\alpha}_{1}\left(\alpha_{2}\right):=2 \hat{\alpha}-\alpha_{2}
$$

denote the value of $\alpha_{1}$ which, for a given value of $\alpha_{2}$, results in an average probability of contracting with a low-cost firm equal to $\hat{\alpha}$.

Proposition 2 Under a uniform wholesale tariff, (i) $q_{L}^{D}=q^{J S}\left(c_{L}\right)$, and (ii) $q_{H}^{U}\left(\alpha_{\Sigma}\right)=\hat{q}^{U}\left(\alpha_{\Sigma}\right)$ if $\alpha_{1}<\hat{\alpha}_{1}\left(\alpha_{2}\right)$ and zero otherwise.

\subsection{Welfare}

We now turn to the welfare implications of banning price discrimination. Welfare, which in general depends on the pricing regime and is ex ante stochastic, is defined as the sum of consumer and producer surplus, $W=\sum_{i=1}^{2}\left\{\int_{0}^{q_{i}} P(z) d z-\left(c_{i}+K\right) q_{i}\right\}$. Let the difference in expected welfare between the discriminatory pricing regime and the uniform pricing regime be $\Delta W:=E\left[W^{D}\right]-E\left[W^{U}\right]$. Since there is no-distortion-at-the-top under either regime, $\Delta W$ depends only on the quantities produced by high-cost retailers. Formally,

$$
\begin{aligned}
\Delta W:= & \Delta W\left(\alpha_{1}, \alpha_{2}\right) \\
& =\sum_{i=1}^{2}\left(1-\alpha_{i}\right)\left[\int_{q_{H}^{U}\left(\alpha_{1}+\alpha_{2}\right)}^{q_{H}^{D}\left(\alpha_{i}\right)} P(z) d z-\left(c_{H}+K\right)\left(q_{H}^{D}\left(\alpha_{i}\right)-q_{H}^{U}\left(\alpha_{1}+\alpha_{2}\right)\right)\right] .
\end{aligned}
$$

According to the following lemma, the quantity offered to high-cost firms under uniform pricing, which is determined by th average probability of contracting with a low-cost firm, is bracketed by the quantities offered to the high-cost types under price discrimination, which are determined by the individual probability of producing at low cost. 
Lemma $3 q_{H}^{D}\left(\alpha_{1}\right) \leq q_{H}^{U}\left(\alpha_{\Sigma}\right) \leq q_{H}^{D}\left(\alpha_{2}\right)<q^{J S}\left(c_{H}\right)$.

Thus, from Propositions 1 and 2 it follows that we can distinguish the following four cases, as depicted in Figure 1:

(I) $0<q_{H}^{D}\left(\alpha_{1}\right)<q_{H}^{U}\left(\alpha_{\Sigma}\right)<q_{H}^{D}\left(\alpha_{2}\right)$, which holds if $\alpha_{2}<\alpha_{1}<\hat{\alpha}$;

(II) $0=q_{H}^{D}\left(\alpha_{1}\right)<q_{H}^{U}\left(\alpha_{\Sigma}\right)<q_{H}^{D}\left(\alpha_{2}\right)$, which holds if $\alpha_{2}<\hat{\alpha} \leq \alpha_{1}<\hat{\alpha}_{1}\left(\alpha_{2}\right)$;

(III) $0=q_{H}^{D}\left(\alpha_{1}\right)=q_{H}^{U}\left(\alpha_{\Sigma}\right)<q_{H}^{D}\left(\alpha_{2}\right)$, which holds if $\alpha_{2}<\hat{\alpha} \leq \hat{\alpha}_{1}\left(\alpha_{2}\right) \leq \alpha_{1}$;

(IV) $0=q_{H}^{D}\left(\alpha_{1}\right)=q_{H}^{U}\left(\alpha_{\Sigma}\right)=q_{H}^{D}\left(\alpha_{2}\right)$, which holds if $\hat{\alpha} \leq \alpha_{2}<\alpha_{1}$.

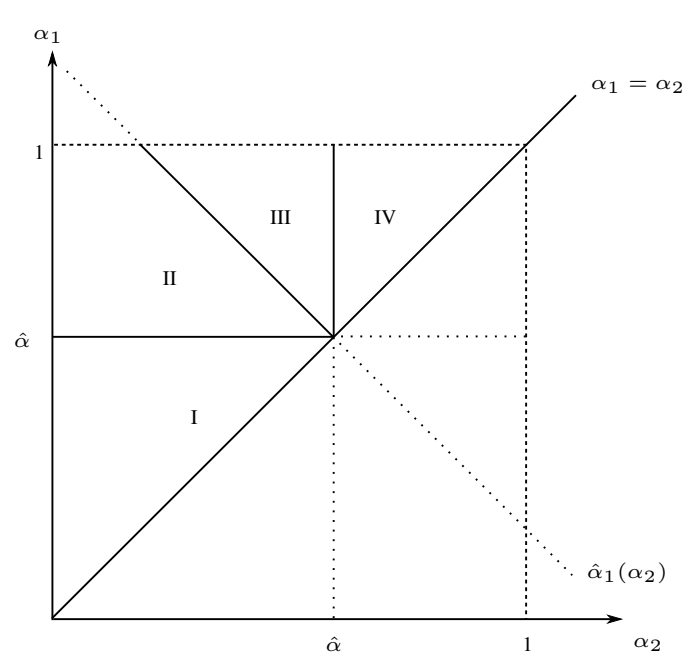

Figure 1: Welfare comparison.

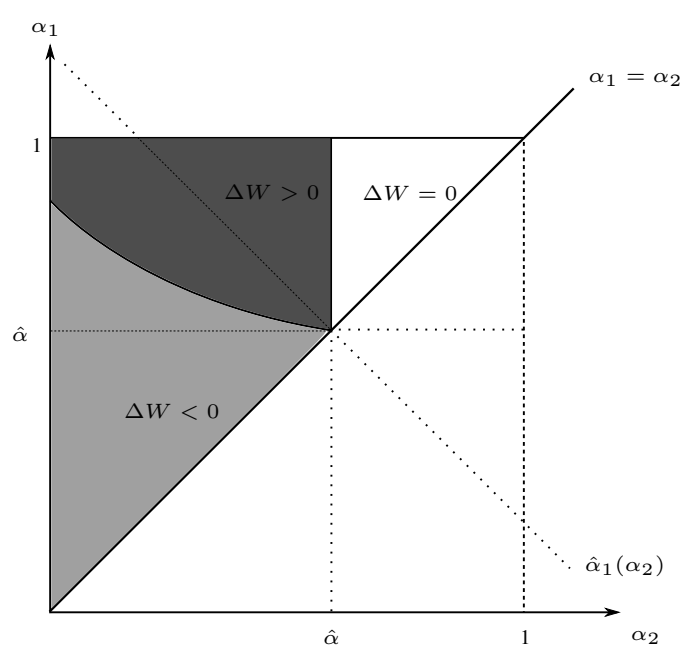

Figure 2: Linear demand.

In case (IV), with $M$ never serving a high-cost downstream firm irrespective of the pricing regime, we trivially have $\Delta W=0$. Therefore, in what follows we focus on cases (I) - (III), i.e., we restrict attention to $\alpha_{2}<\hat{\alpha}$.

Define the expected change in quantity as $\Delta Q:=E\left[Q^{D}\right]-E\left[Q^{U}\right]$, where $Q^{r}$ denotes the aggregate quantity of the final good produced under pricing regime $r \in\{D, U\}$. With this notation, we are prepared to state the main finding of this section.

Proposition 3 Suppose that $\alpha_{2}<\hat{\alpha}$. If

(i) $\alpha_{1}<\hat{\alpha}_{1}\left(\alpha_{2}\right)$, then $\Delta Q \leq 0$ implies $\Delta W<0$;

(ii) $\alpha_{1} \geq \hat{\alpha}_{1}\left(\alpha_{2}\right)$, then $\Delta W>0$.

Moreover, for $\hat{\alpha}<\alpha_{1}<\hat{\alpha}_{1}\left(\alpha_{2}\right) \Delta W$ is strictly increasing in $\alpha_{1}$.

What is the intuition behind the welfare results presented in Proposition 3? In case (III)—part (ii) of Proposition 3-to cut back on information rents, $M$ assigns a zero quantity to the highcost type of firm 1 under price discrimination and to high-cost downstream firms in general under uniform pricing. With high-cost production never taking place under uniform pricing, price discrimination leads to more markets being served (in expectation), thereby benefiting welfare in the spirit of the classic Chicago school argument against non-discrimination clauses.

In cases (I) and (II) - part (ii) of Proposition 3-it is not clear which pricing regime results in higher expected welfare due to opposing effects. In the case of high-cost production, the quantity sold in market 2 is lower under uniform pricing than under price discrimination whereas 
the quantity sold in market 1 is higher under uniform pricing than under price discriminationmarket 1 is not even served under price discrimination in case (II). Even though a general welfare result cannot be derived in these cases, we can establish a sufficient condition—resembling Schmalensee's (1981) output test-for uniform pricing to improve welfare: if price discrimination does not lead to an expansion of expected total output, then expected welfare dincreases if price discrimination is banned. ${ }^{15}$

The conjecture that banning price discrimination can be welfare enhancing is supported by analyzing case (II) in more detail. According to the final statement of Proposition 3, in case (II), the difference in expected welfare between the two pricing regimes decreases as the probability of firm 1 to be the low-cost type decreases. This finding suggests that banning price discrimination - even with more sophisticated pricing schemes being at the manufacturer's disposal — can switch in case (II) from being detrimental for welfare to being welfare enhancing. In case (II), both markets are always served under uniform pricing, whereas under price discrimination market 1 is served only when firm 1 produces at low cost. Banning price discrimination - and thus ensuring that both markets are served irrespective of realized retail efficiencies, however, comes at the cost of a more severe downward distortion in the quantity sold in market 2 in the case of high costs. Since the manufacturer trades off minimizing information rents paid to low-cost types versus maximizing the surplus generated with high-cost types, the downward distortion in quantity $q_{H}^{U}$ becomes more pronounced as it becomes more likely that firm 1 is a low-cost firm. Thus, in case (II), for high values of $\alpha_{1}$ we would expect welfare to be lower under uniform pricing than under price discrimination because of a much stronger downward distortion in the quantity offered to firm 2's high-cost type. If $\alpha_{1}$ is low, on the other hand, then the negative effect of banning price discrimination on $q_{H}^{U}$ is small and the positive effect of more markets being served should outbalance. While not to be obtained in general, as we will show next, this conjecture holds true for a linear demand function.

\subsection{An Application with Linear Demand}

Suppose the inverse demand function is linear, $P(q)=\max \{0,1-q\}$, and assume that $c_{H}+$ $K<1$. In this case, it is readily verified that $q^{J S}\left(c_{H}\right)=\frac{1-c_{H}-K}{2}, q_{H}^{D}(\alpha)=\max \left\{0, q^{J S}\left(c_{H}\right)-\right.$ $\left.\frac{\alpha}{1-\alpha} \frac{c_{H}-c_{L}}{2}\right\}$, and $q_{H}^{U}\left(\alpha_{\Sigma}\right)=\max \left\{0, q^{J S}\left(c_{H}\right)-\frac{\alpha_{\Sigma} / 2}{1-\alpha_{\Sigma} / 2} \frac{c_{H}-c_{L}}{2}\right\}$. A linear inverse demand function allows us to rewrite the difference in expected welfare as

$$
\Delta W=\sum_{i=1}^{2}\left(1-\alpha_{i}\right)\left(q_{H}^{D}\left(\alpha_{i}\right)-q_{H}^{U}\left(\alpha_{\Sigma}\right)\right)\left[\left(1-c_{H}-K\right)-\frac{q_{H}^{D}\left(\alpha_{i}\right)+q_{H}^{U}\left(\alpha_{\Sigma}\right)}{2}\right] .
$$

Tedious but straightforward calculations then yield the following result.

Proposition 4 Suppose $P(q)=\max \{0,1-q\}, c_{H}+K<1$, and $\alpha_{2}<\hat{\alpha}$. Let $\alpha_{1}^{W}\left(\alpha_{2}\right)$ be implicitly defined by $\Delta W\left(\alpha_{1}^{W}\left(\alpha_{2}\right), \alpha_{2}\right) \equiv 0$. Then,

(i) $\Delta W<0$ for $\alpha_{1}<\alpha_{1}^{W}\left(\alpha_{2}\right)$;

(ii) $\Delta W>0$ for $\alpha_{1}>\alpha_{1}^{W}\left(\alpha_{2}\right)$.

${ }^{15}$ This insight is well-known from the literature analyzing third-degree price discrimination in final goods markets. A series of papers elaborates on Schmalensee's basic insight, see Varian (1985), Schwartz (1990), Malueg (1993), and Aguirre et al. (2010). 
In summary, there exists a unique cutoff, $\alpha_{1}^{W}\left(\alpha_{2}\right)$, below which banning price discrimination strictly improves welfare. As is proved in the Appendix, this threshold, which passes through $\left(\alpha_{1}, \alpha_{2}\right)=(\hat{\alpha}, \hat{\alpha})$, is strictly decreasing in $\alpha_{2}$ with a slope strictly between -1 and 0 , as is illustrated in Figure 2.

Part (i) of Proposition 4 is in contrast to findings in the extant literature on third-degree price discrimination under nonlinear wholesale tariffs: without private information of downstream firms, a ban on price discrimination is found to unambiguously reduce welfare if the manufacturer is not restricted to linear prices. Inderst and Shaffer (2009), for instance, consider a manufacturer who is perfectly informed about the retail costs of two asymmetric downstream firms. This manufacturer offers each downstream firm a different two-part tariff under price discrimination, but is restricted to offer only a single two-part tariff under uniform pricing. In this framework, a ban on price discrimination reduces welfare. For the case of separate marketsProposition 6 of Inderst and Shaffer-the optimal discriminatory two-part tariffs maximize the profits of the integrated structure: both marginal wholesale prices equal the manufacturer's marginal production costs and the manufacturer extracts the generated profits fully via the franchise fees because there is no asymmetric information. Under uniform pricing the manufacturer faces a trade-off between efficiency and rent extraction, which leads him to charge a marginal wholesale price above marginal cost of production. As a result, both downstream firms acquire a quantity lower than the optimal quantities from the integrated structurer's point of view, which reduces welfare. Our finding shows that the strong welfare result of Inderst and Shaffer is an artifact of the symmetric information case. Suppose $\alpha_{2}$ is close to zero and $\alpha_{1}$ is close to one but below $\alpha_{1}^{W}(\cdot)$. In this scenario, downstream firm 1 is very likely to be a low-cost firm and downstream firm 2 is very likely to be a high-cost firm. ${ }^{16}$ Thus, this scenario is close to the separate markets case analyzed by Inderst and Shaffer. Nevertheless, according to Proposition 4 , when downstream firms have private information, a ban on price discrimination increases welfare, which is the complete opposite to the finding of Inderst and Shaffer (2009). In this sense, introducing only "little" asymmetric information can fundamentally alter previous welfare results.

What do we learn from Proposition 4 for a case-based approach regarding discriminatory nonlinear wholesale tariffs? If the regulation authority need not be overly concerned about the possibility of one or the other market not being served under either pricing regime, then-at least for linear demand-banning price discrimination is socially desirable. Remember that the area where both markets are served irrespective of the pricing regime is quite large if the difference in retail costs between a high-cost and a low-cost firm is relatively low, i.e., $\hat{\alpha}$ is large. Thus, for relatively small differences in ex post retail costs and if the demand function is sufficiently linear in the relevant range of prices, then usual legal practice in the EU and the US-which is to perceive the application of different wholesale conditions for identical transactions with different trading partners as illegal—often improves welfare.

\footnotetext{
${ }^{16}$ Since $\alpha_{1}^{W}(0)<1$, the likelihood of firm 1 being a low-cost firm cannot be arbitrarily close to 1 . Note, however, that $\alpha$, which increases as the difference in possible retail costs decreases, imposes a lower bound for $\alpha_{1}^{W}(0)$.
} 


\subsection{Private Information about Demand}

Our model can also be interpreted as a model where downstream firms are privately informed about their own demand rather than their marginal cost of production. Suppose that downstream firms are symmetric regarding their production cost, i.e., each downstream firm produces with constant marginal cost $c_{L}$. There are, however, two potential states of demand for each downstream firm, a low-demand state and a high-demand state. A downstream firm in the highdemand state faces (inverse) demand $P(q)$. A downstream firm in the low-demand state, on the other hand, faces (inverse) demand $\tilde{P}(q)=\max \left\{P(q)-\left(c_{H}-c_{L}\right), 0\right\}$, i.e., downstream demand is shifted downward by an amount $c_{H}-c_{L}$. Obviously, the profits of a downstream firm in the high-demand state are identical to those of a low-cost downstream firm in our previous analysis where downstream firms are privately informed about their respective cost of production, $\pi(q$; high demand $)=\pi\left(q ; c_{L}\right)$. Likewise, the profit of a downstream firm in the low-demand state coincides with the profits of a high-cost downstream firm in our previous analysis, ${ }^{17}$

$$
\pi(q ; \text { low demand })=\left[\tilde{P}(q)-c_{L}\right] q=\left[P(q)-c_{H}\right] q=\pi\left(q ; c_{H}\right) .
$$

Which demand state a particular downstream firm faces is assumed to be private information of that downstream firm. Letting $\alpha_{i}$ denote the ex ante probability that firm $i$ is in the high-demand state, we assume that $\alpha_{2}<\alpha_{1}$. Since the ex ante profit functions are the same as in the case of private information regarding downstream production cost, downstream behavior is unchanged and the optimal wholesale mechanism is identical under both interpretations. Moreover, welfare in the high-demand market is $W(q$; high demand $)=\int_{0}^{q} P(q) d q-q c_{L}$ and in the low-demand market is

$$
W(q ; \text { low demand })=\int_{0}^{q} \tilde{P}(q) d q-q c_{L}=\int_{0}^{q} P(q) d q-q c_{H} .
$$

Thus, also welfare is unaffected by this reinterpretation of the model such that our results do not change when downstream firms are privately informed regarding their demand conditions.

\section{LONG-RUN ANALYSIS}

For linear wholesale prices, DeGraba (1990) pointed out a further channel through which differences in the pricing regime can translate into differences in social welfare: with the more efficient downstream firm being discriminated against, price discrimination leads to lower incentives for downstream firms to invest into a more efficient retail technology, thereby harming welfare not only in the short run but also in the long run. In this section, we show that a ban on price discrimination increases downstream firms' incentives to invest into cost reduction also when nonlinear wholesale contracts are in place. ${ }^{18}$

Specifically, suppose that initially both downstream firms produce at high cost with certainty. At some preliminary stage 0 , before the manufacturer makes its offers, both downstream firms

\footnotetext{
${ }^{17}$ Though somewhat imprecise, this statement is correct for the relevant range where downstream profits are nonnegative. A similar qualification applies below regarding welfare in a low-demand market.

${ }^{18}$ In order to maintain our formulation of privately informed downstream firms, we do not follow the usual notion that a downstream firm can reduce its production costs with certainty when investing a given amount of money, but allow for a stochastic R\&D technology.
} 
can simultaneously invest into $R \& D$. If the research of a downstream firm is successful, then this downstream firm produces at low cost $c_{L}$; otherwise, this downstream firm continues to operate at high cost $c_{H}$. Suppose that if a downstream firm incurs investment cost $\psi(\alpha)$, then the research is successful with probability $\alpha$, where $\psi(0)=\psi^{\prime}(0)=0$ and $\psi^{\prime \prime}(\cdot) \geq 0 .{ }^{19}$ Thus, in a sense, $\alpha$ reflects a downstream firm's research intensity. The investment into R\&D is observed by the manufacturer. Whether the research was successful, however, is private information of each downstream firm. We focus on symmetric equilibria in pure strategies. In order to obtain a clear-cut finding with respect to the difference in investment incentives under the two pricing regimes, we assume that downstream marginal revenue is concave.

Assumption $13 P^{\prime \prime \prime}(q)+q P^{\prime \prime}(q) \leq 0$, whenever $P>0$.

Remember that transfers charged by the manufacturer are pinned down by $\left(\mathrm{IR}_{H}\right)$ and $\left(\mathrm{IC}_{L}\right)$. Given R\&D intensities $\alpha_{i}$ and $\alpha_{j}$, downstream firm $i$ 's expected profit at the investment stage under pricing regime $r \in\{D, U\}$ is

$$
\pi_{0}^{r}\left(\alpha_{i}\right)=\alpha_{i}\left(c_{H}-c_{L}\right) q_{H}^{r}\left(\alpha_{i}, \alpha_{j}\right)-\psi\left(\alpha_{i}\right),
$$

where $q_{H}^{r}\left(\alpha_{i}, \alpha_{j}\right)$ denotes the quantity offered to firm $i$ 's high-cost type under pricing regime $r$. Taking the derivative of (19) with respect to $\alpha_{i}$ yields the following first-order condition:

$$
q_{H}^{r}\left(\alpha_{i}, \alpha_{j}\right)\left(c_{H}-c_{L}\right)+\alpha_{i}\left(c_{H}-c_{L}\right) \frac{\partial q_{H}^{r}\left(\alpha_{i}, \alpha_{j}\right)}{\partial \alpha_{i}}=\psi^{\prime}\left(\alpha_{i}\right)
$$

How strong the quantity assigned to the high-cost type of downstream firm $i$ reacts to a change in the probability of this downstream firm producing at low cost depends on the pricing regime.

Price Discrimination.-Under price discrimination, we have $q_{H}^{D}\left(\alpha_{i}, \alpha_{j}\right)=q_{H}^{D}\left(\alpha_{i}\right)$, as defined in Proposition 1. Here, each downstream firm solves an independent optimization problem at the investment stage. Obviously, the optimal investment intensity under price discrimination satisfies $\alpha^{D} \in(0, \hat{\alpha})$, such that $q_{H}^{D}(\alpha)$ is characterized by (10). Inserting $d q_{H}^{D} / d \alpha_{i}$-obtained by differentiating (10) with respect to $\alpha_{i}$-into the first-order condition (20) yields

$$
q_{H}^{D}\left(\alpha^{D}\right)\left(c_{H}-c_{L}\right)+\frac{\alpha^{D}}{\left(1-\alpha^{D}\right)^{2}} \frac{\left(c_{H}-c_{L}\right)^{2}}{2 P^{\prime}\left(q_{H}^{D}\left(\alpha^{D}\right)\right)+q_{H}^{D}\left(\alpha^{D}\right) P^{\prime \prime}\left(q_{H}^{D}\left(\alpha^{D}\right)\right)}=\psi^{\prime}\left(\alpha^{D}\right) .
$$

Equation (21) implicitly characterizes the optimal investment level of a downstream firm under price discrimination. Notice, we have assumed that the downstream marginal revenue is decreasing, i.e., $2 P^{\prime}(\cdot)+q P^{\prime \prime}(\cdot)<0$ whenever $P>0$.

Uniform Pricing.-Under uniform pricing, the quantity assigned to a high-cost downstream firm depends on both firms' investment levels, $q_{H}^{U}\left(\alpha_{i}, \alpha_{j}\right)=q_{H}^{U}\left(\alpha_{\Sigma}\right)$. Thus, the optimal investment of a downstream firm depends not only on its own but also on its rival's investment.

\footnotetext{
${ }^{19}$ For the case of zero investment cost, $\psi\left(\alpha_{i}\right) \equiv 0$, we assume that if a downstream firm is indifferent between several investment levels, it chooses the lowest of these investment levels. For $2 \hat{\alpha}<1$, this tie-breaking rule allows us to avoid unintuitive equilibria under uniform pricing in which both downstream firms choose very high investment levels-because, given firm $j$ 's very high investment level, firm $i$ 's choice of investment has no influence on the quantity allocation - and makes zero profits in equilibrium.
} 
Obviously, the investment level in a symmetric equilibrium $\alpha^{U}<\hat{\alpha}$, and thus $q_{H}\left(\alpha_{\Sigma}\right)$ is defined by (14). By taking the partial derivative of (14) with respect to $\alpha_{i}$, we obtain $\partial q_{H}^{U} / \partial \alpha_{i}$. The investment level in a symmetric equilibrium under uniform pricing, $\alpha^{U}$, is implicitly characterized by

$$
q_{H}^{U}\left(2 \alpha^{U}\right)\left(c_{H}-c_{L}\right)+\frac{\alpha^{U}}{2\left(1-\alpha^{U}\right)^{2}} \frac{\left(c_{H}-c_{L}\right)^{2}}{2 P^{\prime}\left(q_{H}^{U}\left(2 \alpha^{U}\right)\right)+q_{H}^{U}\left(2 \alpha^{U}\right) P^{\prime \prime}\left(q_{H}^{U}\left(2 \alpha^{U}\right)\right)}=\psi^{\prime}\left(\alpha^{U}\right),
$$

which is obtained by inserting $\partial q_{H}^{U} / \partial \alpha_{i}$ into (20).

Investment Incentives.-On the one hand, a higher investment makes it more likely that the downstream firm produces at low costs, and thus obtains a positive information rent. On the other hand, the information rent decreases in a downstream firm's investment, because the quantity assigned to a high-cost firm is decreasing in the investment level. Under price discrimination the expected information rent of firm $i$ depends only on its own investment level, whereas under uniform pricing it depends on the average investment level of both firms. This makes the manufacturer reacting more strongly-i.e., by cutting back this firm's information rent more severely - to an increased investment of firm $i$ under price discrimination than under uniform pricing. In consequence, permitting discriminatory wholesale contracts stifles downstream firms' incentives to invest into a reduction of their production or retail costs.

Proposition 5 Suppose that Assumption 1 holds. A downstream firm's investment into cost reduction is higher under uniform pricing than under price discrimination, i.e., $0<\alpha^{D}<\alpha^{U}$.

Welfare.-With investment incentives being higher under uniform pricing than under price discrimination, it stands to reason that in the long run banning price discrimination is socially beneficial. While we do not show this in generality, the next finding establishes this conjecture for a specification with linear demand and zero investment cost.

Proposition 6 Suppose that demand is linear and there are no investment costs, i.e., $P(q)=$ $\max \{1-q, 0\}$ and $\psi(\alpha) \equiv 0$ for all $\alpha \in[0,1]$. Then, in the long run, welfare is higher under uniform pricing than under price discrimination.

In the long run, with $\alpha^{D}<\alpha^{U}<\hat{\alpha}$, both cost types of both downstream firms are always served. Moreover, with investment incentives being higher under uniform pricing than under price discrimination, a firm is more likely to produce at low cost under uniform pricing. This effect supports welfare under uniform pricing compared to price discrimination. With higher investment incentives under uniform pricing, however, the downward distortion in quantity for a high-cost firm is higher which reduces welfare under uniform pricing compared to price discrimination. According to Proposition 6, however, the direct effect due to an increased probability of producing at low costs outweighs the indirect effect of a higher quantity distortion, thereby making a ban on price discrimination socially desirable in the long-run.

A final remark is in order: with investment incentives being higher under uniform pricing than under price discrimination and in consequence expected gains from trade being higher under uniform pricing, banning price discrimination can also be in the interest of the manufacturer. Uniform pricing can be a valuable commitment device for the manufacturer not to exploit the relationship specific investment of a downstream firm-at least not as much as under price discrimination-and thereby reduces the hold-up problem. 


\section{Continuous Distribution of Downstream Costs}

In this section, we allow for the marginal cost of production of downstream firm $i \in\{1,2\}$ being continuously distributed, i.e., $c \in\left[c_{L}, c_{H}\right] \equiv \mathcal{C}$ with $0 \leq c_{L}<c_{H}$. Firm $i$ 's cost is ex ante distributed according to c.d.f. $F_{i}(c)$ and density $f_{i}(c)>0$ for all $c \in \mathcal{C}$. We assume that the cost distributions of the two firms are different in the sense that there exist values of $c \in \mathcal{C}$ such that $F_{1}(c) / f_{1}(c) \neq F_{2}(c) / f_{2}(c)$. The two ex ante distributions are known by the upstream manufacturer, who offers downstream firm $i$ a direct mechanism $\Gamma_{i} \equiv\left\langle\left(q_{i}(c), t_{i}(c)\right)\right\rangle_{c \in \mathcal{C}}$. For each feasible type announcement mechanism $\Gamma_{i}$ specifies a quantity $q_{i}(c) \in \mathbb{R}_{\geq 0}$ and a transfer $t_{i}(c)$ from firm $i$ to the manufacturer. With the main purpose of this continuous-cost case being to demonstrate robustness of our welfare findings, we focus on linear demand $P(q)=$ $\max \{1-q, 0\}$. The manufacturer's expected profit is given by:

$$
\Pi=\sum_{i=1}^{2}\left\{\int_{c_{L}}^{c_{H}}\left[t_{i}(c)-K q_{i}(c)\right] f_{i}(c) d c\right\} .
$$

As before the manufacturer has to satisfy the individual rationality and incentive compatibility constraints: for all $i \in\{1,2\}$ and $c \in \mathcal{C}$,

$$
\begin{aligned}
& q_{i}(c)\left[1-q_{i}(c)-c\right]-t_{i}(c) \geq 0 \\
& c \in \arg \max _{\tilde{c} \in \mathcal{C}}\left\{q_{i}(\tilde{c})\left[1-q_{i}(\tilde{c})-c\right]-t_{i}(\tilde{c})\right\} .
\end{aligned}
$$

If price discrimination is banned, then the manufacturer has to satisfy the additional constraint $\Gamma_{1}=\Gamma_{2}$. Note that for the manufacturer it is more profitable to contract with low-cost downstream firms. This implies that the usual monotonicity requirement, which is necessary to satisfy incentive compatibility, here requires that $q_{i}(c)$ and $t_{i}(c)$ are non-increasing. As it is wellknown, without further assumptions on the type distribution this monotonicity requirement may be binding which makes the analysis by far more complicated. In this respect, we impose the following assumption in the spirit of the monotone hazard rate property.

Assumption 2 For all $c \in \mathcal{C}$ it holds that $F_{i}(c) / f_{i}(c)$, with $i \in\{1,2\}$, and $\left[F_{1}(c)+F_{2}(c)\right] /\left[f_{1}(c)\right.$ $+f_{2}(c)$ ] are non-decreasing.

Note that Assumption 2 is satisfied if both density functions display weakly decreasing densities.

Moreover, we focus on cases where-irrespective of the pricing regime-the manufacturer serves all types of downstream firms, which corresponds to case (I) in the previous analysis. The following assumption guarantees that this is the case under the optimal mechanisms.

Assumption $3 c_{H}+K<1-\left[\min \left\{f_{1}\left(c_{H}\right), f_{2}\left(c_{H}\right)\right\}\right]^{-1}$.

As before, superscripts $D$ and $U$ denote the pricing regime: price discrimination and uniform pricing, respectively.

Lemma 4 Suppose that Assumptions 2 and 3 hold. If $q_{i}^{D}(c)<q_{j}^{D}(c)$ for $i, j \in\{1,2\}$ and $i \neq j$, then $q^{U}(c) \in\left(q_{i}^{D}(c), q_{j}^{D}(c)\right)$. 
According to Lemma 4, one market benefits from price discrimination whereas the other market is harmed compared to uniform pricing for a given cost realization. Nevertheless, for linear demand we obtain a clear welfare result.

Proposition 7 Suppose that Assumptions 2 and 3 hold. A ban on price discrimination improves total welfare, i.e., $\Delta W<0$.

\section{Downstream Competition}

So far, we restricted attention to downstream firms operating in separate markets. Modeling downstream competition raises the following concerns: Regarding the information structure, does each downstream firm know its competitor's cost type or only its own type? In the former case, the manufacturer can use a mechanism that severely punishes both downstream firms if their reports regarding their own and their competitor's cost types do not match, thereby revealing the downstream firms' private information without cost. With this type of mechanism being feasible under both pricing regimes, there is no scope for analyzing the welfare effects of banning price discrimination. If, on the other hand, downstream firms know only their own cost types, then the quantity offered to a downstream firm may nevertheless depend on both downstream firms' reports. Under price discrimination, for example, the manufacturer now has eight quantities and eight transfers to specify which raises analytical complexity. Besides being by far less tractable, contracts with a firm's transfer depending on quantities procured by both firms seem hard to reconcile with observed practice. ${ }^{20}$ But even restricting contracts such that a firm's transfers and quantities depend only on its own type does not circumvent the question whether a firm learns its competitor's type before or after accepting the upstream firm's offer, i.e., whether ex ante or ex post participation constraints matter.

In order to address robustness of our results with regard to downstream competition, we pursue the last of the above approaches: within a differentiated-goods framework, a firm's contract may depend only on its own type, and at the contracting stage downstream firms only know the distribution of their competitor's cost. Following Dixit (1979) and Singh and Vives (1984), we consider a representative consumer with utility function

$$
U\left(q_{1}, q_{2}\right)=q_{1}-\frac{1}{2} q_{1}^{2}+q_{2}-\frac{1}{2} q_{2}^{2}-\gamma q_{1} q_{2}-p_{1} q_{1}-p_{2} q_{2},
$$

where $\gamma \in[0,1]$. The parameter $\gamma$ measures to what extent the products of the two downstream firms are substitutes: for $\gamma=0$, we are back in the case of separate markets, whereas for $\gamma=1$ downstream firms produce perfect substitutes. The resulting inverse demand function for the commodity produced by firm $i \in\{1,2\}$ is

$$
P\left(q_{i}, q_{j}\right)=1-q_{i}-\gamma q_{j}, \quad i \neq j .
$$

We focus on cases where both downstream firms are served. In this regard we assume $\alpha_{1}<$ $\hat{\alpha}:=\left(1-c_{H}-K\right) /\left(1-c_{L}-K\right)$. Moreover, we restrict attention to situations where the

\footnotetext{
${ }^{20}$ Regarding contracts where "retailers' payments [...] depend on their own and their rivals' actions [...], [t]here are many reasons why such contracts may not be feasible, ranging from the costs of enforcement to illegality under the antitrust statutes." (O’Brien and Shaffer 1994, p.298)
} 
free-disposal constraint has no bite, i.e., none of the input offered by $M$ goes to waste. Let $E_{j}[q]=\alpha_{j} q_{j L}+\left(1-\alpha_{j}\right) q_{j H}$ denote the expected quantity sold by firm $j$. Without referring to a specific pricing regime, the individual rationality and incentive compatibility constraints regarding downstream firm $i \neq j$ resemble those in the analysis of separate markets but now the expected quantity of firm $i$ 's downstream rival also plays a role:

$$
\begin{aligned}
& q_{i H}\left(1-q_{i H}-\gamma E_{j}[q]-c_{H}\right)-t_{i H} \geq 0 \\
& q_{i L}\left(1-q_{i L}-\gamma E_{j}[q]-c_{L}\right)-t_{i L} \geq 0 \\
& q_{i H}\left(1-q_{i H}-\gamma E_{j}[q]-c_{H}\right)-t_{i H} \geq q_{i L}\left(1-q_{i L}-\gamma E_{j}[q]-c_{H}\right)-t_{i L} \\
& q_{i L}\left(1-q_{i L}-\gamma E_{j}[q]-c_{L}\right)-t_{i L} \geq q_{i H}\left(1-q_{i H}-\gamma E_{j}[q]-c_{L}\right)-t_{i H}
\end{aligned}
$$

Obviously, incentive compatibility imposes the usual monotonicity requirement, $q_{i H} \leq q_{i L}$, and $\left(\mathrm{IR}_{i L}\right)$ holds whenever $\left(\mathrm{IR}_{i H}\right)$ and $\left(\mathrm{IC}_{i L}\right)$ are satisfied.

In contrast to the case of separate markets, under price discrimination the manufacturer does not solve two independent maximization problems anymore. Nevertheless, following standard procedure works here as well, i.e., upstream profits are maximized over quantities subject to the above constraints with transfers being pinned down by $\left(\mathrm{IR}_{i H}\right)$ and $\left(\mathrm{IC}_{i L}\right)$. In the optimum, $M$ offers quantities smaller than in the case of separate markets,

$$
q_{i L}^{D}(\gamma)=q^{J S}\left(c_{L}\right)-\frac{\gamma}{1+\gamma} q^{J S}\left(c_{H}\right)
$$

and

$$
q_{i H}^{D}(\gamma)=\frac{1}{1+\gamma} q^{J S}\left(c_{H}\right)-\frac{\alpha_{i}}{1-\alpha_{i}} \frac{c_{H}-c_{L}}{2}
$$

thereby —at least partly—internalizing the externality of downstream competition. Note that the monotonicity requirement is satisfied. Moreover, if the products are sufficiently differentiated, then $M$ wants to serve both firms and the quantity offered to either firm is that low such that free disposal does not impose a binding restriction. Formally, letting $q_{i}\left(q_{j} \mid c_{i}\right)$ denote firm $i$ 's best reply to firm $j$ 's quantity when producing at $\operatorname{cost} c_{i}$ itself, the following holds:

Lemma 5 Let $q_{j} \in\left\{q_{j L}^{D}(\gamma), q_{j H}^{D}(\gamma)\right\}$. There exists $\gamma^{D} \in(0,1]$ such that, for $\gamma<\gamma^{D}$, (i) $0<q_{i H}^{D}(\gamma)<q_{i L}^{D}$, and $(i i) q_{i H}^{D}(\gamma)<q_{i}\left(q_{j} \mid c_{H}\right)$ and $q_{i L}^{D}(\gamma)<q_{i}\left(q_{j} \mid c_{L}\right)$.

Under uniform pricing, next to the above individual rationality and incentive compatibility constraints for each firm, $M$ faces the additional constraint that $q_{1 L}=q_{2 L}=q_{L}$ and $q_{1 H}=q_{2 H}=q_{H}$. With incentive compatibility requiring monotonicity, $q_{H} \leq q_{L}$, it follows that $E_{1}[q] \geq E_{2}[q]$. In consequence, whenever a particular cost type of firm 2 is willing to accept $M$ 's contract offer, so is that cost type of firm 1. Likewise, downward incentive compatibility with regard to firm 2 implies downward incentive compatibility with regard to firm 1. Therefore, with $\left(\mathrm{IR}_{2 H}\right)$ and $\left(\mathrm{IC}_{2 L}\right)$ are more pressing than $\left(\mathrm{IR}_{1 H}\right)$ and $\left(\mathrm{IC}_{1 L}\right)$, respectively, standard procedure corresponds to setting transfers that make $\left(\mathrm{IR}_{2 H}\right)$ and $\left(\mathrm{IC}_{2 L}\right)$ bind. ${ }^{21}$ Maximizing upstream profits—with transfers being determined by $\left(\mathrm{IR}_{2 H}\right)$ and $\left(\mathrm{IC}_{2 L}\right)$-results in $M$

\footnotetext{
${ }^{21}$ While upward incentive compatibility regarding firm 1 is not satisfied in general under the resulting choice of transfers, for $\gamma$ not too large it can be shown that $\left(\mathrm{IC}_{1 H}\right)$ holds when $\left(\mathrm{IC}_{2 L}\right)$ binds.
} 
offering quantities

$$
\begin{aligned}
q_{L}^{U}(\gamma)= & q^{J S}\left(c_{L}\right) \frac{4 \alpha_{\Sigma}\left(2-\alpha_{\Sigma}\right)\left(1+\gamma\left(1-\alpha_{1}\right)\right)}{\Lambda(\gamma)} \\
& -\gamma \frac{\left[\alpha_{\Sigma}\left(1-\alpha_{1}\right)+\left(2-\alpha_{\Sigma}\right) \alpha_{1}\right]\left[\left(2-\alpha_{\Sigma}\right)\left(1-c_{H}-K\right)-\alpha_{\Sigma}\left(c_{H}-c_{L}\right)\right]}{\Lambda(\gamma)}
\end{aligned}
$$

and

$$
\begin{array}{r}
q_{H}^{U}(\gamma)=q^{J S}\left(c_{H}\right) \frac{4 \alpha_{\Sigma}\left(2-\alpha_{\Sigma}\right)\left(1+\gamma \alpha_{1}\right)}{\Lambda(\gamma)}-\left(c_{H}-c_{L}\right) \frac{2\left(\alpha_{\Sigma}\right)^{2}\left(1+\gamma \alpha_{1}\right)}{\Lambda(\gamma)} \\
-\gamma \frac{\left[\alpha_{\Sigma}\left(1-\alpha_{1}\right)+\left(2-\alpha_{\Sigma}\right) \alpha_{1}\right] \alpha_{\Sigma}\left(1-c_{H}-K\right)}{\Lambda(\gamma)}
\end{array}
$$

where

$$
\Lambda(\gamma)=4 \alpha_{\Sigma}\left(2-\alpha_{\Sigma}\right)(1+\gamma)-\gamma^{2}\left(\alpha_{\Sigma}-2 \alpha_{1}\right)^{2}
$$

As stated in the following lemma, if the degree of substitutability is not too high, then the above quantities are strictly positive (i.e., $M$ wants to serve both firms), satisfy the monotonicity requirement, and free disposal has no bite.

Lemma 6 Let $q_{j} \in\left\{q_{j L}^{D}(\gamma), q_{j H}^{D}(\gamma)\right\}$. There exists $\gamma^{U} \in(0,1]$ such that, for $\gamma<\gamma^{U}$, (i) $0<q_{H}^{U}(\gamma)<q_{L}^{U}(\gamma)$, and (ii) $q_{H}^{U}(\gamma)<q_{i}\left(q_{j} \mid c_{H}\right)$ and $q_{L}^{U}(\gamma)<q_{i}\left(q_{j} \mid c_{L}\right)$.

With transfers being welfare neutral, for a given degree of product differentiation $\gamma$, welfare under pricing regime $r \in\{D, U\}$ amounts to

$$
W^{r}(\gamma)=\sum_{i=1}^{2}\left(1-\frac{1}{2} q_{i}^{r}(\gamma)-c_{i}-K\right) q_{i}^{r}(\gamma)-\gamma q_{1}^{r}(\gamma) q_{2}^{r}(\gamma)
$$

Since for $\gamma=0$ we are back in the case of separate markets with linear (inverse) demand, from Proposition 4(i) it follows that the difference in expected welfare under both pricing regimes is strictly negative, $\Delta W<0$. With the quantities characterized by (30), (31), (32), and (33) changing smoothly in $\gamma$, the following result follows from continuity of $W^{r}(\gamma)$.

Proposition 8 Suppose $\alpha_{1}<\hat{\alpha}$. There exists $\gamma^{W} \in\left(0, \min \left\{\gamma^{D}, \gamma^{U}\right\}\right]$ such that $\Delta W(\gamma)<0$ for $\gamma<\gamma^{W}$.

In summary, as long as downstream competition is not overly intense-in the sense of downstream firms competing in sufficiently differentiated commodities—banning price discrimination improves welfare.

\section{Demand-Side Substitution}

As was recently shown by Inderst and Valletti (2009) and Caprice (2005), the implications of price discrimination in input markets for pricing decisions and welfare may be reversed if the assumption of a monopolistic input supplier is relaxed. We augment our basic model with separate markets by allowing for downstream firms to purchase the essential input not only 
from the manufacturer but also from an alternative source. As we will show, the main effect of this outside option is to shift rents from the manufacturer to the downstream firms. As a result, by and large, our findings are robust toward relaxing the assumption of a monopolistic input supplier.

Following Katz (1987) and Inderst and Valletti (2009), we suppose that a downstream firm, when rejecting the manufacturer's offer, can turn to an alternative source of input supply. How profitable this switch to the alternative supply is for a particular downstream firm depends on its efficiency in production. If a firm with marginal cost $c \in\left\{c_{L}, c_{H}\right\}$ acquires its input from the alternative supply, then its profits are $\pi^{A}(c)$, with $0 \leq \pi^{A}\left(c_{H}\right)<\pi^{A}\left(c_{L}\right) .{ }^{22,23}$ We assume that the alternative source of input supply is not too attractive in the sense that the joint surplus generated by $M$ and either type of downstream firm exceeds that downstream firm's profit obtained under the alternative supply.

Assumption 4 For all $c \in\left\{c_{L}, c_{H}\right\}$ it holds that: $\pi\left(q^{J S}(c), c\right)-K q^{J S}(c)>\pi^{A}(c)$.

We define

$$
\phi:=\frac{\pi^{A}\left(c_{L}\right)-\pi^{A}\left(c_{H}\right)}{c_{H}-c_{L}}
$$

which declares how much more a low-cost firm benefits from the alternative input supply than a high-cost firm, relative to the low-cost firm's cost advantage. ${ }^{24}$ In order to stick close to our basic model without alternative supply, we keep $c_{L}$ and $c_{H}$ fixed and assume that any variation in $\phi$ arises due to changes in $\pi^{A}\left(c_{L}\right)$ or $\pi^{A}\left(c_{H}\right)$. For reasons of tractability, we assume that the outside option is not superior, in the sense that under the optimal contract it is never the upward incentive constraint that is binding. ${ }^{25}$ Formally, we impose the following assumption:

Assumption $5 \phi \leq q^{J S}\left(c_{L}\right)$.

Otherwise the model is the same as before. In particular, with $M$ still making take-it-orleave-it offers, $M$ 's objective function remains unchanged. Moreover, facing the usual incentive compatibility constraints, the optimal wholesale mechanism still has to satisfy monotonicity constraint (MON) and $t_{L} \geq t_{H}$. The individual rationality constraints, however, are not the same as before due to the existence of an alternative source of supply:

$$
\begin{gathered}
\pi\left(q_{L}, c_{L}\right)-t_{L} \geq \pi^{A}\left(c_{L}\right), \\
\pi\left(q_{H}, c_{H}\right)-t_{H} \geq \pi^{A}\left(c_{H}\right) .
\end{gathered}
$$

Clearly, if $M$ prefers to serve only one cost type, then welfare results require a specification of the alternative input supply. Therefore, in what follows, we restrict attention to cases where $M$

\footnotetext{
${ }^{22}$ One possible interpretation is that there exists a competitive fringe that produces an input good which is substitutable to the manufacturer's product. The downstream firms can acquire this fringe product at a per-unit cost of $\bar{w}>0$. In order to switch input suppliers a downstream firm has to incur a fixed cost $F \geq 0$. With this interpretation we obtain $\pi^{A}\left(c_{i}\right):=\max \left\{0, \max _{q}[P(q)-c-\bar{w}] q-F\right\}$

${ }^{23} \mathrm{Here}$, the manufacturer faces a screening problem with a type-dependent outside option. This class of problems is thoroughly analyzed, for instance, by Jullien $(1996,2000)$.

${ }^{24}$ The case analyzed in Section 4 then corresponds to a special case of the situation where the outside option is equally attractive for both types, i.e., where $\phi=0$.

${ }^{25}$ Thus, we do not consider countervailing incentives in the sense of Lewis and Sappington (1989). Cf. also Tirole (1988, p.154.)
} 
serves both types of downstream firms. This allows us to draw welfare implications irrespective of the particular form the alternative source of supply takes. ${ }^{26}$ In order to state the discussion as concise a possible, define $\alpha^{r}$, with $r \in\{D, U\}$ denoting the pricing regime, as follows: $\alpha^{D}=\alpha_{i}$ for $i \in\{1,2\}$ under price discrimination and $\alpha^{U}=\alpha_{\Sigma}$ under uniform pricing. ${ }^{27}$

Following the analysis of type-dependent participation constraints in Laffont and Martimort (2002), under Assumption 5, we have to distinguish three cases. First, for $\phi \leq \hat{q}\left(\alpha^{r}\right)$, the alternative source of supply is similarly attractive to a high-cost and a low-cost downstream firm. Hence, this case is similar to the standard case without an outside option: the constraints $\left(\mathrm{IR}_{H}^{A}\right)$ and $\left(\mathrm{IC}_{L}\right)$ are binding and the quantities are as in the standard case but the transfers are shifted downwards. Second, for $\hat{q}\left(\alpha^{r}\right)<\phi \leq q^{J S}\left(c_{H}\right)$, to ensure the low-cost downstream firm's participation, it must receive a higher profit than the information rent it receives in the first case. The manufacturer achieves this by increasing the information rent which requires an increase of the quantity offered to a high-cost firm. Formally, the manufacturer chooses $q_{H}$ such that next to $\left(\mathrm{IR}_{H}^{A}\right)$ and $\left(\mathrm{IC}_{L}\right)$ also $\left(\mathrm{IR}_{L}^{A}\right)$ is binding. Last, for $q^{J S}\left(c_{H}\right)<\phi \leq q^{J S}\left(c_{L}\right)$, the outside option is by far more attractive for a low-cost downstream firm than for a highcost downstream firm. Here, the manufacturer does not need to worry about a low-cost firm's incentives but about its participation. The optimal contract now satisfies both participation constraints with equality $\left(\operatorname{IR}_{H}^{A}\right)$ and $\left(\operatorname{IR}_{L}^{A}\right)$ and the incentive constraints are all slack. Hence, in this case, the quantity offered to each cost type equals the respective joint surplus maximizing quantity. ${ }^{28}$

Defining $\alpha^{r}(\phi)$ implicitly by

$$
\hat{q}^{r}\left(\alpha^{r}(\phi)\right) \equiv \phi
$$

the optimal quantities for the manufacturer to offer are summarized in the following proposition. Figure 3 illustrates the above discussion for the discriminatory pricing regime.

Proposition 9 Suppose that Assumptions 4 and 5 hold and that the upstream firm serves both types of downstream firms. The optimal wholesale mechanism under pricing regime $r \in\{D, U\}$ allocates quantities

(i) $q_{L}^{r}\left(\alpha^{r}\right)=q^{J S}\left(c_{L}\right)$ and $q_{H}^{r}\left(\alpha^{r}\right)=\hat{q}^{r}\left(\alpha^{r}\right)$ if $\phi \leq q^{J S}\left(c_{H}\right)$ and $\alpha^{r} \leq \alpha^{r}(\phi)$;

(ii) $q_{L}^{r}\left(\alpha^{r}\right)=q^{J S}\left(c_{L}\right)$ and $q_{H}^{r}\left(\alpha^{r}\right)=\phi$ if $\phi \leq q^{J S}\left(c_{H}\right)$ and $\alpha^{r} \geq \alpha^{r}(\phi)$;

(iii) $q_{L}^{r}\left(\alpha^{r}\right)=q^{J S}\left(c_{L}\right)$ and $q_{H}^{r}\left(\alpha^{r}\right)=q^{J S}\left(c_{H}\right)$ if $q^{J S}\left(c_{H}\right) \leq \phi \leq q^{J S}\left(c_{L}\right)$.

Regarding the welfare effects of banning price discrimination in the presence of an alternative source of input supply, we distinguish two cases: (a) $\phi \in\left[q^{J S}\left(c_{H}\right), q^{J S}\left(c_{L}\right)\right]$, and (b) $\phi<$ $q^{J S}\left(c_{H}\right)$.

The welfare implications of banning price discrimination in case (a) are trivial: The quantities offered are the same under both pricing regimes, which implies $\Delta W=0$.

\footnotetext{
${ }^{26} \mathrm{~A}$ precise account under what circumstances $M$ indeed prefers to serve both cost types of downstream firms is given in Appendix B.

${ }^{27}$ Under price discrimination the manufacturer solves two independent maximization problems; one for each downstream firm $i \in\{1,2\}$. With a slight abuse of notation, we suppress the subscript $i$ for the discriminatory pricing regime.

${ }^{28}$ Since we do not allow for countervailing incentives, we do not encounter an upward distortion of the more efficient firm's quantity.
} 


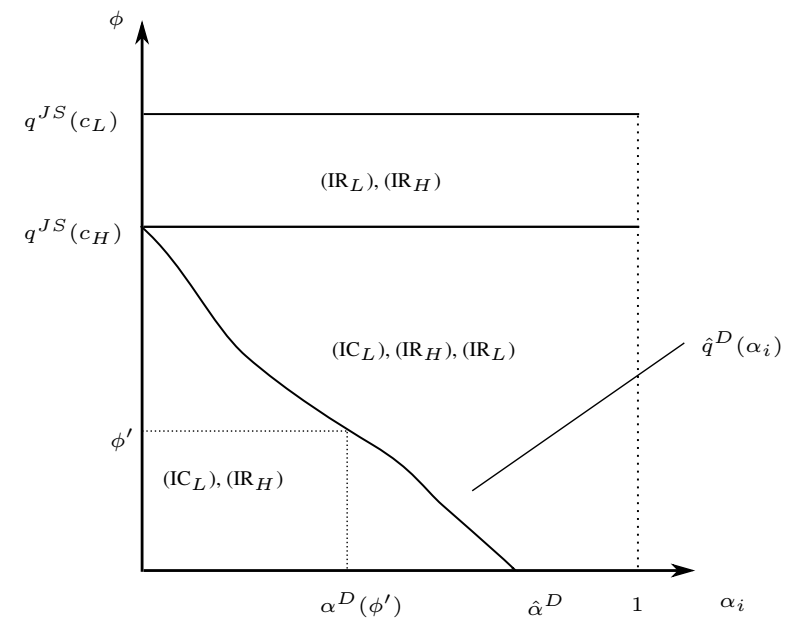

Figure 3: Binding constraints when $M$ serves both types.

In case (b), while $M$ still prefers to serve both types of each downstream firm under either regime and offers $q^{J S}\left(c_{L}\right)$ to any low-cost downstream firm, the quantity offered to a highcost downstream firm depends on both the pricing regime and its ex ante efficiency. More precisely, under price discrimination firm $i$, when producing at high cost, is offered quantity $q_{H}^{D}\left(\alpha_{i}\right)=\hat{q}^{D}\left(\alpha_{i}\right)$ if $\alpha_{i} \leq \alpha^{D}(\phi)$ and quantity $q_{H}^{D}\left(\alpha_{i}\right)=\phi$ otherwise. Under uniform pricing $M$ offers $q_{H}^{U}\left(\alpha_{\Sigma}\right)=\hat{q}^{U}\left(\alpha_{\Sigma}\right)$ if $\alpha_{\Sigma} \leq \alpha^{U}(\phi)$ and $q_{H}^{U}\left(\alpha_{\Sigma}\right)=\phi$ otherwise. Define

$$
\alpha_{1}^{U}\left(\alpha_{2} ; \phi\right):=\alpha^{U}(\phi)-\alpha_{2},
$$

and note that $\alpha_{1}^{U}\left(\alpha^{D}(\phi) ; \phi\right)=\alpha^{D}(\phi)$. This gives rise to four cases similar to the four cases depicted in Figure 1. For $\alpha_{2}>\alpha^{D}(\phi)$ the quantities offered by $M$ are identical under both pricing regimes such that $\Delta W=0$. The welfare implications for the remaining cases parallel those drawn in the standard model without an alternative source of input supply.

Proposition 10 Suppose Assumptions 4 and 5 hold and that $\phi<q^{J S}\left(c_{H}\right)$. (i) If $\alpha_{2}<$ $\alpha^{D}(\phi) \leq \alpha_{1}^{U}\left(\alpha_{2} ; \phi\right) \leq \alpha_{1}$, then $\Delta W>0$. (ii) If $\alpha_{2}<\alpha^{D}(\phi)<\alpha_{1}<\alpha_{1}^{U}\left(\alpha_{2} ; \phi\right)$, then $\Delta W$ is strictly decreasing in $\alpha_{1}$. (iii) If $\alpha_{2}<\alpha_{1} \leq \alpha^{D}(\phi)$, then $\Delta W<0$ for $P(q)=\max \{1-q, 0\}$.

The intuition behind the welfare result of Proposition 10 is basically the same as the one behind Proposition 3. Due to the outside option rents are shifted from the manufacturer to the downstream firms, but this shift does not affect total welfare as long as no downstream firm acquires its input from the fringe supply. Proposition 10 shows that our previous findings are robust toward relaxing the assumption of an unconstrained manufacturer. In particular, if the potential differences in retail costs are low, then a ban on price discrimination improves welfare at least for linear demand, where $\alpha^{D}(\phi)=\left[q^{J S}\left(c_{H}\right)-\phi\right] /\left[q^{J S}\left(c_{L}\right)-\phi\right]$ approaches 1 as $c_{H}$ tends to $c_{L}$.

Regarding a case-based approach of banning discriminatory wholesale contracts, Proposition 10 provides a justification for the competition authority to ban discriminatory wholesale contracts if concerned with a primary-line injury case. Put differently, if a competitor of a dominant manufacturer files a complaint that the dominant manufacturer uses discriminatory 
wholesale tariffs, then the competition policy agency often is well advised to condemn this pricing practice. Banning discriminatory wholesale contracts is advisable, however, not to protect competitors of the dominant manufacturer but to protect consumers.

\section{CONCLUSION}

In this paper, we analyze a vertically related industry with asymmetric information between the upstream and the downstream sector. The main purpose is to inquire into the welfare effects of banning third-degree price discrimination in intermediate-good markets when nonlinear pricing schemes are feasible. This question is of immediate practical interest because from a legal perspective, quantity discounts are commonly regarded as a justifiable pricing strategy of manufacturers or wholesale firms as long as they are not discriminatory in the sense of applying different conditions to identical transactions with other trading partners.

While there has been considerable back and forth in the academic literature regarding the question whether banning price discrimination in intermediate-good markets constitutes a desirable course of policy when wholesale prices are linear, among the few exceptions which consider nonlinear wholesale pricing schemes the predominant opinion is that banning discriminatory wholesale pricing is detrimental for welfare. In contrast to these findings, we show that even if nonlinear pricing schemes are feasible, the reservation toward discriminatory pricing practices embodied in legal enactments may well be warranted when downstream firms have private information. This result holds irrespective of whether geographic price discrimination, primary-line injury or secondary-line injury is considered.

\section{A. Proofs of Propositions AND LEMmas}

\section{Proof of Lemma 1:}

First, suppose $q^{\prime}<q^{\prime \prime}<q^{*}\left(c_{H}\right)$. Then

$$
\begin{aligned}
& \pi\left(q^{\prime \prime}, c_{L}\right)-\pi\left(q^{\prime}, c_{L}\right)>\pi\left(q^{\prime \prime}, c_{H}\right)-\pi\left(q^{\prime}, c_{H}\right) \\
& \quad \Longleftrightarrow\left[P\left(q^{\prime \prime}\right)-c_{L}\right] q^{\prime \prime}-\left[P\left(q^{\prime}\right)-c_{L}\right] q^{\prime}>\left[P\left(q^{\prime \prime}\right)-c_{H}\right] q^{\prime \prime}-\left[P\left(q^{\prime}\right)-c_{H}\right] q^{\prime} \\
& \quad \Longleftrightarrow q^{\prime}<q^{\prime \prime} .
\end{aligned}
$$

Next, suppose $q^{\prime}<q^{*}\left(c_{H}\right) \leq q^{\prime \prime} \leq q^{*}\left(c_{L}\right)$. Then

$$
\begin{gathered}
\pi\left(q^{\prime \prime}, c_{L}\right)-\pi\left(q^{\prime}, c_{L}\right)>\pi\left(q^{\prime \prime}, c_{H}\right)-\pi\left(q^{\prime}, c_{H}\right)=\pi\left(q^{*}\left(c_{H}\right), c_{H}\right)-\pi\left(q^{\prime}, c_{H}\right) \\
\Longleftrightarrow \quad\left[P\left(q^{\prime \prime}\right)-c_{L}\right] q^{\prime \prime}-\left[P\left(q^{\prime}\right)-c_{L}\right] q^{\prime}>\left[P\left(q^{*}\left(c_{H}\right)\right)-c_{H}\right] q^{*}\left(c_{H}\right)-\left[P\left(q^{\prime}\right)-c_{H}\right] q^{\prime} \\
\Longleftrightarrow \quad\left[P\left(q^{\prime \prime}\right)-c_{L}\right] q^{\prime \prime}-\left[P\left(q^{*}\left(c_{H}\right)\right)-c_{L}\right] q^{*}\left(c_{H}\right)+\left[P\left(q^{*}\left(c_{H}\right)\right)-c_{L}\right] q^{*}\left(c_{H}\right) \\
\quad-\left[P\left(q^{\prime}\right)-c_{L}\right] q^{\prime}>\left[P\left(q^{*}\left(c_{H}\right)\right)-c_{H}\right] q^{*}\left(c_{H}\right)-\left[P\left(q^{\prime}\right)-c_{H}\right] q^{\prime} \\
\Longleftrightarrow \quad \pi\left(q^{\prime \prime}, c_{L}\right)-\pi\left(q^{*}\left(c_{H}\right), c_{L}\right)+\left(c_{H}-c_{L}\right)\left(q^{*}\left(c_{H}\right)-q^{\prime}\right)>0,
\end{gathered}
$$

where the last inequality holds by $q^{\prime}<q^{*}\left(c_{H}\right) \leq q^{\prime \prime} \leq q^{*}\left(c_{L}\right)$ and $\pi\left(q, c_{L}\right)$ being strictly increasing in $q$ on $q \in\left[0, q^{*}\left(c_{L}\right)\right)$.

Last, suppose $q^{*}\left(c_{H}\right) \leq q^{\prime}<q^{\prime \prime} \leq q^{*}\left(c_{L}\right)$. Then

$$
\pi\left(q^{\prime \prime}, c_{L}\right)-\pi\left(q^{\prime}, c_{L}\right)>\pi\left(q^{\prime \prime}, c_{H}\right)-\pi\left(q^{\prime}, c_{H}\right)=\pi\left(q^{*}\left(c_{H}\right), c_{H}\right)-\pi\left(q^{*}\left(c_{H}\right), c_{H}\right)=0
$$


holds because $\pi\left(q, c_{L}\right)$ is strictly increasing in $q$ on $q \in\left[0, q^{*}\left(c_{L}\right)\right)$.

\section{Proof of Lemma 3:}

Inspection of the first-order conditions (10) and (14), together with the definition of $q^{J S}(c)$ and the fact that

$$
\alpha_{2}<\alpha_{1} \Longrightarrow \frac{\alpha_{2}}{1-\alpha_{2}}<\frac{\alpha_{1}+\alpha_{2}}{2-\alpha_{1}-\alpha_{2}}<\frac{\alpha_{1}}{1-\alpha_{1}}
$$

immediately implies $\hat{q}^{D}\left(\alpha_{1}\right)<\hat{q}^{U}\left(\alpha_{1}+\alpha_{2}\right)<\hat{q}^{D}\left(\alpha_{2}\right)<q^{J S}\left(c_{H}\right)$. The desired statement then follows from Propositions 1 and 2.

\section{Proof of Proposition 3:}

We prove each part of the proposition in turn. To cut back on notation, we will make use of the following notation: $q_{H i}^{D}:=q_{H}^{D}\left(\alpha_{i}\right)$ for $i \in\{1,2\}$, and $q_{H}^{U}:=q_{H}^{U}\left(\alpha_{\Sigma}\right)$.

(i) Note that the expected total output under price discrimination and under uniform pricing is given by,

$$
E\left[Q^{D}\right]=\alpha_{1} q_{L}^{D}\left(\alpha_{1}\right)+\left(1-\alpha_{1}\right) q_{H}^{D}\left(\alpha_{1}\right)+\alpha_{2} q_{L}^{D}\left(\alpha_{2}\right)+\left(1-\alpha_{2}\right) q_{H}^{D}\left(\alpha_{2}\right)
$$

and

$$
E\left[Q^{U}\right]=\alpha_{1} q_{L}^{U}\left(\alpha_{\Sigma}\right)+\left(1-\alpha_{1}\right) q_{H}^{U}\left(\alpha_{\Sigma}\right)+\alpha_{2} q_{L}^{U}\left(\alpha_{\Sigma}\right)+\left(1-\alpha_{2}\right) q_{H}^{U}\left(\alpha_{\Sigma}\right)
$$

respectively. Thus, $\Delta Q:=E\left[Q^{D}\right]-E\left[Q^{U}\right]$ is given by

$$
\Delta Q=\left(1-\alpha_{2}\right)\left[q_{H 2}^{D}-q_{H}^{U}\right]-\left(1-\alpha_{1}\right)\left[q_{H}^{U}-q_{H 1}^{D}\right] .
$$

The change in expected welfare can be rewritten as follows,

$$
\Delta W=\left(1-\alpha_{2}\right) \int_{q_{H}^{U}}^{q_{H 2}^{D}} P(z) d z-\left(1-\alpha_{1}\right) \int_{q_{H 1}^{D}}^{q_{H}^{U}} P(z) d z-\left(c_{H}+K\right) \Delta Q .
$$

By the usual argument, we can find an upper bound for the first term and a lower bound for the second term (see Varian, 1985). Hence, the change in expected welfare is bounded from above by

$$
\Delta W<\left(1-\alpha_{2}\right) P\left(q_{H}^{U}\right)\left[q_{H 2}^{D}-q_{H}^{U}\right]-\left(1-\alpha_{1}\right) P\left(q_{H}^{U}\right)\left[q_{H}^{U}-q_{H 1}^{D}\right]-\left(c_{H}+K\right) \Delta Q .
$$

Rearranging the above inequality yields,

$$
\Delta W<\left[P\left(q_{H}^{U}\left(\alpha_{\Sigma}\right)\right)-\left(c_{H}+K\right)\right] \Delta Q .
$$

We conclude by noting that $\left[P\left(q_{H}^{U}\right)-\left(c_{H}+K\right)\right]>0$ because $q^{J S}\left(c_{H}\right)>q_{H}^{U} \geq 0$.

(ii) With $\hat{\alpha}_{1}\left(\alpha_{2}\right) \leq \alpha_{1}$, we have $q_{H 1}^{D}=q_{H}^{U}=0<q_{H 2}^{D}=\hat{q}^{D}\left(\alpha_{2}\right)$. According to (16), the difference in expected welfare under the two pricing regimes is

$$
\Delta W=\left(1-\alpha_{2}\right)\left[\int_{0}^{q_{H 2}^{D}} P(z) d z-\left(c_{H}+K\right) q_{H 2}^{D}\right] .
$$


The desired result then follows from the first-order condition (10) together with $P^{\prime}(\cdot)<0$ whenever $P(\cdot)>0$ :

$$
\begin{aligned}
& P\left(q_{H 2}^{D}\right)-\left(c_{H}+K\right)=-P^{\prime}\left(q_{H 2}^{D}\right) q_{H 2}^{D}+\frac{\alpha}{1-\alpha}\left(c_{H}-c_{L}\right)>0 \\
& \Longrightarrow\left[P\left(q_{H 2}^{D}\right)-\left(c_{H}+K\right)\right] q_{H 2}^{D}>0 \\
& \Longrightarrow \int_{0}^{q_{H 2}^{D}} P(z) d z-\left(c_{H}+K\right) q_{H 2}^{D}>0
\end{aligned}
$$

Last, we prove the final statement, i.e, in case (II), $\Delta W$ is strictly increasing in $\alpha_{1}$. With $\alpha_{2}<\hat{\alpha}<\alpha_{1}<\hat{\alpha}_{1}\left(\alpha_{2}\right)$, we have $q_{H 1}^{D}=0<q_{H}^{U}=\hat{q}^{U}\left(\alpha_{\Sigma}\right)<q_{H 2}^{D}=\hat{q}^{D}\left(\alpha_{2}\right)$. Note that $d q_{H 1}^{D} / d \alpha_{1}=0$. Differentiation of (16) w.r.t. $\alpha_{1}$ yields

$$
\frac{d \Delta W}{d \alpha_{1}}=\left[\int_{0}^{q_{H}^{U}} P(z) d z-\left(c_{H}+K\right) q_{H}^{U}\right]-\left(2-\alpha_{\Sigma}\right) \frac{d q_{H}^{U}}{d \alpha_{1}}\left[P\left(q_{H}^{U}\right)-\left(c_{H}+K\right)\right]
$$

With $q_{H}^{U}=\hat{q}^{U}\left(\alpha_{\Sigma}\right)$ being defined by (14), we have $d q_{H}^{U} / d \alpha_{1}<0$. Moreover, with $P^{\prime}(\cdot)<0$ whenever $P(\cdot)>0$, from (14) it follows that

$$
\begin{aligned}
P\left(q_{H}^{U}\right)-\left(c_{H}+K\right)=-P^{\prime}\left(q_{H}^{U}\right) q_{H}^{U}+\frac{\alpha_{\Sigma}}{2-\left(\alpha_{\Sigma}\right)}\left(c_{H}-c_{L}\right)>0 \\
\Longrightarrow \int_{0}^{q_{H}^{U}} P(z) d z-\left(c_{H}+K\right) q_{H}^{U}>0 .
\end{aligned}
$$

Taken together, these observations allow us to conclude that $d \Delta W / d \alpha_{1}>0$.

\section{Proof of Proposition 4:}

With $\Delta W$ being given by (17), we consider in turn each of the three relevant cases identified in the main text : (I) $\alpha_{2}<\alpha_{1}<\hat{\alpha}$; (II) $\alpha_{2}<\hat{\alpha} \leq \alpha_{1}<\hat{\alpha}_{1}\left(\alpha_{2}\right)$; and (III) $\alpha_{2}<\hat{\alpha}<\hat{\alpha}_{1}\left(\alpha_{2}\right) \leq$ $\alpha_{1}$. To cut back on notation, we will make use of the following notation: $q_{H i}^{D}:=q_{H}^{D}\left(\alpha_{i}\right)$ for $i \in\{1,2\}, q_{H}^{U}:=q_{H}^{U}\left(\alpha_{\Sigma}\right), q_{H}^{J S}:=q^{J S}\left(c_{H}\right)$, and $\Delta_{c}:=c_{H}-c_{L}$.

(I) With $\alpha_{2}<\alpha_{1}<\hat{\alpha}$ we have $q_{H i}^{D}=q_{H}^{J S}-\frac{\alpha_{i}}{1-\alpha_{i}} \frac{\Delta_{c}}{2}$ and $q_{H}^{U}=q_{H}^{J S}-\frac{\alpha_{\Sigma}}{2-\alpha_{\Sigma}} \frac{\Delta_{c}}{2}$. Noting that $\Delta Q=\left[\sum_{i=1,2}\left(1-\alpha_{i}\right) q_{H i}^{D}\right]-\left(2-\alpha_{\Sigma}\right) q_{H}^{U}=0, \Delta W<0$ follows from Proposition 3(ii).

(II) With $\alpha_{2}<\hat{\alpha} \leq \alpha_{1}<\hat{\alpha}_{1}\left(\alpha_{2}\right)$, we have $q_{H 1}^{D}=0, q_{H 2}^{D}=q_{H}^{J S}-\frac{\alpha_{2}}{1-\alpha_{2}} \frac{\Delta_{c}}{2}$ and $q_{H}^{U}=$ $q_{H}^{J S}-\frac{\alpha_{\Sigma}}{2-\left(\alpha_{\Sigma}\right)} \frac{\Delta_{c}}{2}$. The difference in expected welfare thus equals

$$
\begin{aligned}
\Delta W=\left(1-\alpha_{2}\right) q_{H 2}^{D}\left\{1-\frac{1}{2} q_{H 2}^{D}-\left(c_{H}\right.\right. & +K)\} \\
& -\left(2-\alpha_{\Sigma}\right) q_{H}^{U}\left\{1-\frac{1}{2} q_{H}^{U}-\left(c_{H}+K\right)\right\} .
\end{aligned}
$$

Let $\alpha_{1}^{W}\left(\alpha_{2}\right)$ be implicitly defined by

$$
\Delta W\left(\alpha_{1}^{W}\left(\alpha_{2}\right), \alpha_{2}\right) \equiv 0
$$


Differentiation of A.15 with respect to $\alpha_{2}$ reveals that

$$
\begin{gathered}
\frac{d \alpha_{1}^{W}\left(\alpha_{2}\right)}{d \alpha_{2}}\left[-\left(2-\alpha_{\Sigma}\right) \frac{d q_{H}^{U}}{d \alpha_{\Sigma}}\left\{1-q_{H}^{U}-\left(c_{H}+K\right)\right\}+q_{H}^{U}\left\{1-\frac{1}{2} q_{H}^{U}-\left(c_{H}+K\right)\right\}\right] \\
=-\left(1-\alpha_{2}\right) \frac{d q_{H 2}^{D}}{d \alpha_{2}}\left(\left\{1-q_{H 2}^{D}-\left(c_{H}+K\right)\right\}+q_{H 2}^{D}\left\{1-\frac{1}{2} q_{H 2}^{D}-\left(c_{H}+K\right)\right\}\right. \\
\quad+\left(2-\alpha_{\Sigma}\right) \frac{d q_{H}^{U}}{d \alpha_{\Sigma}}\left\{1-q_{H}^{U}-\left(c_{H}+K\right)\right\}-q_{H}^{U}\left\{1-\frac{1}{2} q_{H}^{U}-\left(c_{H}+K\right)\right\}
\end{gathered}
$$

Substituting for $q_{H 2}^{D}$ and $q_{H}^{U}$, and noting that $\frac{d q_{H 2}^{D}}{d \alpha_{2}}=-\frac{1}{\left(1-\alpha_{2}\right)^{2}} \frac{\Delta_{c}}{2}$ and $\frac{d q_{H}^{U}}{d \alpha_{\Sigma}}=-\frac{2}{\left(2-\alpha_{\Sigma}\right)^{2}} \frac{\Delta_{c}}{2}$ yields

$$
\begin{aligned}
\frac{d \alpha_{1}^{W}\left(\alpha_{2}\right)}{d \alpha_{2}}\left[\frac{2}{2-\alpha_{\Sigma}}\right. & \frac{\Delta_{c}}{2}\left\{q_{H}^{J S}+\frac{\alpha_{\Sigma}}{2-\alpha_{\Sigma}} \frac{\Delta_{c}}{2}\right\} \\
+ & \left.\left\{q_{H}^{J S}-\frac{\alpha_{\Sigma}}{2-\alpha_{\Sigma}} \frac{\Delta_{c}}{2}\right\}\left\{\frac{3}{2} q_{H}^{J S}+\frac{1}{2} \frac{\alpha_{\Sigma}}{2-\alpha_{\Sigma}} \frac{\Delta_{c}}{2}\right\}\right] \\
& =\left[\frac{1}{1-\alpha_{2}} \frac{\Delta_{c}}{2}\left\{q_{H}^{J S}+\frac{\alpha_{2}}{1-\alpha_{2}} \frac{\Delta_{c}}{2}\right\}\right. \\
& \left.+\left\{q_{H}^{J S}-\frac{\alpha_{2}}{1-\alpha_{2}} \frac{\Delta_{c}}{2}\right\}\left\{\frac{3}{2} q_{H}^{J S}+\frac{1}{2} \frac{\alpha_{2}}{1-\alpha_{2}} \frac{\Delta_{c}}{2}\right\}\right] \\
& -\left[\frac{2}{2-\alpha_{\Sigma}} \frac{\Delta_{c}}{2}\left\{q_{H}^{J S}+\frac{\alpha_{\Sigma}}{2-\alpha_{\Sigma}} \frac{\Delta_{c}}{2}\right\}\right. \\
+ & \left.\left\{q_{H}^{J S}-\frac{\alpha_{\Sigma}}{2-\alpha_{\Sigma}} \frac{\Delta_{c}}{2}\right\}\left\{\frac{3}{2} q_{H}^{J S}+\frac{1}{2} \frac{\alpha_{\Sigma}}{2-\alpha_{\Sigma}} \frac{\Delta_{c}}{2}\right\}\right]
\end{aligned}
$$

A first important observation is that each term in square brackets is strictly positive, which implies that $d \alpha_{1}^{W}\left(\alpha_{2}\right) / d \alpha_{2}>-1$. Moreover, all the terms with $q_{H}^{J S}$ on the RHS of (A.17) cancel out, which allows us to rewrite (A.17) as follows:

$$
\begin{aligned}
\frac{d \alpha_{1}^{W}\left(\alpha_{2}\right)}{d \alpha_{2}}\left[\frac{2}{2-\alpha_{\Sigma}} \frac{\Delta_{c}}{2}\left\{q_{H}^{J S}+\frac{\alpha_{\Sigma}}{2-\alpha_{\Sigma}} \frac{\Delta_{c}}{2}\right\}\right. \\
\left.+\left\{q_{H}^{J S}-\frac{\alpha_{\Sigma}}{2-\alpha_{\Sigma}} \frac{\Delta_{c}}{2}\right\}\left\{\frac{3}{2} q_{H}^{J S}+\frac{1}{2} \frac{\alpha_{\Sigma}}{2-\alpha_{\Sigma}} \frac{\Delta_{c}}{2}\right\}\right] \\
=\left(\frac{\Delta_{c}}{2}\right)^{2}\left\{\frac{\alpha_{2}\left(2-\alpha_{2}\right)}{\left(1-\alpha_{2}\right)^{2}}-\frac{\alpha_{\Sigma}\left[4-\alpha_{\Sigma}\right]}{\left(2-\alpha_{\Sigma}\right)^{2}}\right\}
\end{aligned}
$$

Straightforward manipulation of the RHS yields

$$
\left(\frac{\Delta_{c}}{2}\right)^{2}\left\{\frac{\alpha_{2}\left(2-\alpha_{2}\right)}{\left(1-\alpha_{2}\right)^{2}}-\frac{\alpha_{\Sigma}\left[4-\alpha_{\Sigma}\right]}{\left(2-\alpha_{\Sigma}\right)^{2}}\right\}=\frac{1}{2}\left(\frac{\Delta_{c}}{2}\right)^{2} \frac{\alpha_{\Sigma}^{2}-4 \alpha_{\Sigma}+4 \alpha_{2}\left(2-\alpha_{2}\right)}{\left(1-\alpha_{2}\right)^{2}\left(2-\alpha_{\Sigma}\right)^{2}} .
$$

Since $\alpha_{\Sigma}^{2}-4 \alpha_{\Sigma}+4 \alpha_{2}\left(2-\alpha_{2}\right)<0$ if and only if $\alpha_{1} \in\left(\alpha_{2}, 4-3 \alpha_{2}\right)$, the RHS of (A.18) is strictly negative. Therefore, with the term in square brackets on the LHS of (A.18) being strictly positive, we must have $d \alpha_{1}^{W}\left(\alpha_{2}\right) / d \alpha_{2}<0$. Taken together, the above observations imply

$$
\frac{d \alpha_{1}^{W}\left(\alpha_{2}\right)}{d \alpha_{2}} \in(-1,0)
$$


Last, note that $\alpha_{1}^{W}(\hat{\alpha})=\hat{\alpha}$. To see this, note that for $\alpha_{1}=\alpha_{2}$ we have $q_{H 2}^{D}=q_{H}^{U}$, and in consequence

$$
\begin{aligned}
\Delta W=-\left(1-\alpha_{2}\right) q_{H 2}^{D}\left\{1-\frac{1}{2} q_{H 2}^{D}-\left(c_{H}+K\right)\right\}= \\
-\left(1-\alpha_{2}\right) q_{H 2}^{D}\left\{\frac{3}{2} q_{H}^{J S}+\frac{1}{2} \frac{\alpha_{2}}{1-\alpha_{2}} \frac{\Delta_{c}}{2}\right\} .
\end{aligned}
$$

With $q_{H}^{J S}>0$, for $\Delta W=0$ we must have $q_{H 2}^{D}=0$, which holds for $\alpha_{2}=\hat{\alpha}$. Together with $d \alpha_{1}^{W}\left(\alpha_{2}\right) / d \alpha_{2} \in(-1,0)$ this last observation implies $\alpha_{1}^{W}\left(\alpha_{2}\right) \in\left(\hat{\alpha}, \hat{\alpha}_{1}\left(\alpha_{2}\right)\right)$. The result then follows immediately from the final remark of Proposition 3.

(III) $\Delta W<0$ follows from Proposition 3 (i).

Taken together, the above observations establish the desired result.

\section{Proof of Proposition 5}

First, we show that the equilibrium investment levels are indeed characterized by (21) and (22). Thereafter, we show that comparing (21) and (22) reveals that $\alpha^{D}<\alpha^{U}$.

Consider price discrimination first. Firm $i$ 's expected profit at the contracting stage does not depend on firm $j$ 's investment intensity $\alpha_{j}$ such that $\pi_{0}^{D}\left(\alpha_{i} ; \alpha_{j}\right)=\pi_{0}^{D}\left(\alpha_{i}\right)$. The information rent left to a low-cost downstream firm is zero if its investment level is too high, i.e., $\pi_{0}^{D}\left(\alpha_{i}\right)=0$ for $\alpha_{i} \geq \hat{\alpha}^{D}$. Moreover, $d \pi_{0}^{D}(\alpha) /\left.d \alpha\right|_{\alpha=0}=q_{H}^{J S}(0)\left(c_{H}-c_{L}\right)>0$. Thus, $\alpha^{D} \in\left(0, \hat{\alpha}^{D}\right)$. Finally, note that $\pi_{0}^{D}(\cdot)$ is a continuously differentiable function and thus $\alpha^{D}$ is characterized by the first-order condition (21).

Under uniform pricing the profit of a downstream firm $i$ depends also on the rival's investment level $\alpha_{j}$. If $\alpha_{j}=0$, then firm $i$ chooses a strictly positive investment level because $\partial \pi_{0}^{U}\left(\alpha_{i} ; 0\right) /\left.\partial \alpha_{i}\right|_{\alpha_{i}=0}>0$. For $r=U$, implicitly differentiating (19) with respect to $\alpha_{j}$ reveals

$$
\frac{d \alpha_{i}}{d \alpha_{j}}\left\{2 \frac{\partial \hat{q}_{H}^{U}\left(\alpha_{\Sigma}\right)}{\partial \alpha_{i}}+\alpha_{i} \frac{\partial^{2} \hat{q}_{H}^{U}\left(\alpha_{\Sigma}\right)}{\partial \alpha_{i}^{2}}-\frac{\psi^{\prime \prime}\left(\alpha_{i}\right)}{\left(c_{H}-c_{L}\right)}\right\}=-\frac{\partial \hat{q}_{H}^{U}\left(\alpha_{\Sigma}\right)}{\partial \alpha_{j}}-\alpha_{i} \frac{\partial^{2} \hat{q}_{H}^{U}\left(\alpha_{\Sigma}\right)}{\partial \alpha_{i} \partial \alpha_{j}}
$$

Under Assumption 1, from (14) it follows that

$$
\frac{\partial \hat{q}_{H}^{U}\left(\alpha_{\Sigma}\right)}{\partial \alpha_{i}}=\frac{\partial \hat{q}_{H}^{U}\left(\alpha_{\Sigma}\right)}{\partial \alpha_{j}}=\frac{2\left(c_{H}-c_{L}\right)}{\left(2-\alpha_{\Sigma}\right)^{2}\left[2 P^{\prime}(\cdot)+P^{\prime \prime}(\cdot) \hat{q}_{H}^{U}\left(\alpha_{\Sigma}\right)\right]}<0
$$

and

$$
\begin{aligned}
& \frac{\partial^{2} \hat{q}_{H}^{U}\left(\alpha_{\Sigma}\right)}{\partial \alpha_{i}^{2}}=\frac{\partial^{2} \hat{q}_{H}^{U}\left(\alpha_{\Sigma}\right)}{\partial \alpha_{i} \alpha_{j}}= \\
& \frac{2\left(c_{H}-c_{L}\right)\left\{2\left[2 P^{\prime}(\cdot)+P^{\prime \prime}(\cdot) \hat{q}_{H}^{U}\left(\alpha_{\Sigma}\right)\right]-\left(2-\alpha_{\Sigma}\right)\left[3 P^{\prime \prime}(\cdot)+P^{\prime \prime \prime}(\cdot) \hat{q}_{H}^{U}\left(\alpha_{\Sigma}\right)\right] \frac{\partial \hat{q}_{H}^{U}\left(\alpha_{\Sigma}\right)}{\partial \alpha_{i}}\right\}}{\left(2-\alpha_{\Sigma}\right)^{3}\left[2 P^{\prime}(\cdot)+P^{\prime \prime}(\cdot) \hat{q}_{H}^{U}\left(\alpha_{\Sigma}\right)\right]^{2}}
\end{aligned}
$$

This allows us to conclude that firm $i$ 's best-response function is weakly decreasing-weakly decreasing because it might be the case that firm $i$ chooses $\alpha_{i}=1$ for values of $\alpha_{j}$ sufficiently close to zero or $\alpha_{i}=0$ for values of $\alpha_{j}$ sufficiently close to one. With downstream 
firms being ex ante symmetric, their best-response functions are symmetric. Existence of a symmetric Nash equilibrium with equilibrium investment level $\alpha^{U} \in(0,1)$ then follows from best-response functions being continuous and firm $i$ choosing an investment level strictly less than 1 for $\alpha_{j}$ sufficiently high. To see the latter point, note the following: (i) if $2 \hat{\alpha}<1$, then $\alpha_{i}=0$ is a best response to $\alpha_{j} \in[2 \hat{\alpha}, 1]$ because a higher investment by firm $i$ does not change the quantity allocation, $q_{H}^{U}\left(\alpha_{i}+\alpha_{j}\right)=0$, but comes at higher cost; (ii) if $1<2 \hat{\alpha}$, then $\partial \pi_{0}^{U}\left(\alpha_{i} ; 1\right) /\left.\partial \alpha_{i}\right|_{\alpha_{i}=2 \hat{\alpha}-1}=\alpha_{i}\left(c_{H}-c_{L}\right)^{2} /(2-\hat{\alpha})^{2} P^{\prime}(0)-\psi^{\prime}\left(\alpha_{i}\right)<0$, such that firm $i$ 's best response is smaller than $2 \hat{\alpha}-1$, which itself is smaller than 1 because $\hat{\alpha}<1$ for $c_{H}<c_{L}$. Last, note that any symmetric equilibrium under uniform pricing must have $\alpha^{U}<\hat{\alpha}$ : if $\alpha^{U} \geq 2 \hat{\alpha}$, then firm $i$ 's best response to $\alpha_{j}=\alpha^{U}$ is not $\alpha_{i}=\alpha^{U}$ but $\alpha_{i}=0$; if $\alpha^{U} \in[\hat{\alpha}, 2 \hat{\alpha})$, then firm $i$ can profitably deviate to $\alpha_{i}$ slightly below $2 \hat{\alpha}-\alpha^{U}$, which results in strictly positive expected profits because $q_{H}^{U}\left(\alpha_{i}+\alpha^{U}\right)>0$.

Comparing the equalities (22) and (21) immediately reveals that $\alpha^{D} \neq \alpha^{U}$. Note that for $\alpha^{U}=\alpha^{D}$, we would have $q_{H}^{U}=q_{H}^{D}$. Suppose, in contradiction, that $\alpha^{U}<\alpha^{D}$, which implies that $q_{H}^{U}>q_{H}^{D}$. Let $M R^{\prime}(q) \equiv 2 P^{\prime}(q)+q P^{\prime \prime}(q)$, so that $M R(q)$ denotes the marginal revenue of a downstream firm. With $\psi^{\prime}\left(\alpha^{U}\right) \leq \psi^{\prime}\left(\alpha^{D}\right)$, by hypothesis, it has to hold that

$$
q_{H}^{D}\left(c_{H}-c_{L}\right)+\frac{\alpha^{D}}{\left(1-\alpha^{D}\right)^{2}} \frac{\left(c_{H}-c_{L}\right)^{2}}{M R^{\prime}\left(q_{H}^{D}\right)} \geq q_{H}^{U}\left(c_{H}-c_{L}\right)+\frac{\alpha^{U}}{2\left(1-\alpha^{D}\right)^{2}} \frac{\left(c_{H}-c_{L}\right)^{2}}{M R^{\prime}\left(q_{H}^{U}\right)},
$$

or equivalently,

$$
\left(c_{H}-c_{L}\right)\left(q_{H}^{U}-q_{H}^{D}\right)+\frac{\alpha^{U}}{2\left(1-\alpha^{D}\right)^{2}} \frac{\left(c_{H}-c_{L}\right)^{2}}{M R^{\prime}\left(q_{H}^{U}\right)}-\frac{\alpha^{D}}{\left(1-\alpha^{D}\right)^{2}} \frac{\left(c_{H}-c_{L}\right)^{2}}{M R^{\prime}\left(q_{H}^{D}\right)} \leq 0 .
$$

The above inequality is violated because (a) by hypothesis $\alpha^{U}<\alpha^{D}$ and $q_{H}^{U}>q_{H}^{D}$, and (b) by Assumption $1 M R^{\prime}(q)$ is non-increasing. This completes the proof.

Proof of Proposition 6 For $\phi(\alpha) \equiv 0$ and $P(q)=\max \{1-q, 0\}$, where the latter implies $M R^{\prime}(q)=-2$, it is straightforward to show that the investment level under price discrimination is given by

$$
\alpha^{D}=1-\frac{\sqrt{2 q^{J S}\left(c_{L}\right)\left(c_{H}-c_{L}\right)}}{2 q^{J S}\left(c_{L}\right)} \in(0,1),
$$

with $q^{J S}\left(c_{L}\right)=(1 / 2)\left(1-c_{L}-K\right)$. The symmetric investment level under uniform pricing amounts to

$$
\alpha^{U}=1-\frac{c_{H}-c_{L}+\sqrt{c_{H}-c_{L}} \sqrt{c_{H}-c_{L}+16 q^{J S}\left(c_{L}\right)}}{8 q^{J S}\left(c_{L}\right)} \in\left(\alpha^{D}, 1\right) .
$$

Given our tie-breaking rule that a downstream firm who is indifferent between several investment levels always choses the lowest one, there are no asymmetric equilibria and the symmetric equilibrium is the unique one. In order to see this, let $\alpha_{i}^{R}\left(\alpha_{j}\right)$ be the reaction function of firm $i$. The slope of the reaction function

$$
\frac{d \alpha_{i}^{R}}{d \alpha_{j}}=-\frac{2+\alpha_{i}-\alpha_{j}}{4-2 \alpha_{j}} \in(-1,-1 / 2),
$$


Thus, there is only a symmetric equilibrium because the absolute value of the slope of the reaction function is always less than one.

The difference in expected welfare between price discrimination and uniform pricing is

$$
\begin{aligned}
\Delta W=\frac{1}{16}\left(c_{H}-c_{L}\right)\left[\left(\sqrt{c_{H}-c_{L}}\right)^{2}+3 \sqrt{c_{H}-c_{L}}\right. & \sqrt{c_{H}-c_{L}+16 q^{J S}\left(c_{L}\right)} \\
& \left.-10 \sqrt{2} \sqrt{\left(c_{H}-c_{L}\right) q^{J S}\left(c_{L}\right)}\right] .
\end{aligned}
$$

Thus, $\Delta W<0$ if and only if

$$
\sqrt{c_{H}-c_{L}}+\sqrt{9\left(c_{H}-c_{L}\right)+144 q^{J S}\left(c_{L}\right)}-\sqrt{200 q^{J S}\left(c_{L}\right)}<0,
$$

which holds because $c_{H}<1-K$.

\section{Proof of Lemma 4:}

First, we analyze the manufacturer's screening problem for the continuous distribution of downstream types. Noting that neither the individual rationality constraints nor the incentive compatibility constraints depend on the pricing regime, we begin with drawing out the implications of these constraints for the optimal wholesale tariff. To cut back on notation, we suppress the subscript $i$ indicating the downstream firm.

Define

$$
V(c) \equiv q(c)[1-q(c)-c]-t(c) .
$$

Using a revealed preference argument for types $c, \hat{c} \in \mathcal{C}$ and $\hat{c}>c$ we obtain

$$
q(c) \geq \frac{V(c)-V(\hat{c})}{\hat{c}-c} \geq q(\hat{c}) .
$$

The above chain of inequalities implies that $V^{\prime}(c)=-q(c)$ except for points of discontinuity. Moreover, from (A.32) we immediately obtain that the incentive compatible quantity and transfer schedules, $q(c)$ and $t(c)$, are non-increasing. Using the insights from above, the transfer $t(c)$ can be stated as

$$
t(c)=q(c)[1-q(c)-c]-\int_{c}^{c_{H}} q(z) d z
$$

because $V(c)=V\left(c_{H}\right)-\int_{c}^{c_{H}} q(z) d z$ and $V\left(c_{H}\right)=0$ in the optimum.

Discriminatory Offers.-With downstream firms operating in separate markets, the manufacturer solves two isolated maximization problems. After integrating by parts, the manufacturer's problem regarding firm $i=1,2$ can be stated as follows:

Program D1:

$$
\begin{aligned}
& \max _{\langle q(c)\rangle_{c \in \mathcal{C}}} \int_{c_{L}}^{c_{H}}\left(q(c)[1-q(c)-c-K]-q(c) \frac{F_{i}(c)}{f_{i}(c)}\right) f_{i}(c) d c \\
& \text { subject to: } q(c) \text { is non-increasing }
\end{aligned}
$$


Ignoring the monotonicity constraint for the moment, point-wise maximization yields

$$
q_{i}^{D}(c)=\frac{1}{2}\left[1-c-K-\frac{F_{i}(c)}{f_{i}(c)}\right] .
$$

By Assumptions 2 and 3, the quantity schedule $q_{i}^{D}(c)$ is strictly decreasing and assigns a positive quantity to all types.

Uniform Pricing.-Being restricted to offer the same wholesale tariff to both downstream firms, the manufacturer maximizes

$$
\int_{c_{L}}^{c_{H}}[t(c)-K q(c)]\left[f_{1}(c)+f_{2}(c)\right] d c
$$

subject to the (IC) and (IR) constraints. Since the constraints are the same as under price discrimination, the incentive compatible transfer schedule is still characterized by (A.33). Integrating by parts yields

$$
\int_{c_{L}}^{c_{H}} \int_{c}^{c_{H}} q(z) d z\left[f_{1}(c)+f_{2}(c)\right] d c=\int_{c_{L}}^{c_{H}} q(c)\left[F_{1}(c)+F_{2}(c)\right] d c
$$

such that the manufacturer faces the following problem:

Program U:

$$
\max _{\langle q(c)\rangle_{c \in \mathcal{C}}} \int_{c_{L}}^{c_{H}}\left(q(c)[1-q(c)-c-K]-q(c) \frac{F_{1}(c)+F_{2}(c)}{f_{1}(c)+f_{2}(c)}\right)\left[f_{1}(c)+f_{2}(c)\right] d c
$$

subject to: $q(c)$ is non-increasing

Ignoring the monotonicity constraint for the moment, point-wise maximization yields

$$
q^{U}(c)=\frac{1}{2}\left[1-c-K-\frac{F_{1}(c)+F_{2}(c)}{f_{1}(c)+f_{2}(c)}\right] .
$$

By Assumptions 2 and 3, the quantity schedule $q^{U}(c)$ is strictly decreasing and assigns a positive quantity to all types.

Based on the above insights, we now can prove Lemma 4. According to (A.34), if $q_{1}^{D}(c)<$ $q_{2}^{D}(c)$, then $F(c)_{1} / f(c)_{1}>F(c)_{2} / f(c)_{2}$. In combination with (A.37), $q_{1}^{D}(c)<q^{U}(c)<$ $q_{2}^{D}(c)$ is equivalent to

$$
\frac{F_{1}(c)}{f_{1}(c)}>\frac{F_{1}(c)+F_{2}(c)}{f_{1}(c)+f_{2}(c)}>\frac{F_{2}(c)}{f_{2}(c)} \Longleftrightarrow \frac{F_{1}(c)}{f_{1}(c)}>\frac{F_{2}(c)}{f_{2}(c)},
$$

which establishes the desired result.

\section{Proof of Proposition 7:}

Inserting (A.34) and (A.37) into

$$
\mathbb{E}\left[W^{D}\right]=\sum_{i=1}^{2}\left\{\int_{c_{L}}^{c_{H}}\left[q_{i}^{D}(c)-(1 / 2)\left(q_{i}^{D}(c)\right)^{2}-(c+K) q_{i}^{D}(c)\right] f_{i}(c) d c\right\}
$$


and

$$
\mathbb{E}\left[W^{U}\right]=\int_{c_{L}}^{c_{H}}\left[q^{U}(c)-(1 / 2)\left(q^{U}(c)\right)^{2}-(c+K) q^{U}(c)\right]\left(f_{1}(c)+f_{2}(c)\right) d c,
$$

respectively, reveals

$$
\begin{aligned}
\Delta W= & \frac{1}{8}\left\{\int_{c_{L}}^{c_{H}} f_{1}(c)\left[1-(c+K)-\frac{F_{1}(c)}{f_{1}(c)}\right]\left[\frac{F_{1}(c) f_{2}(c)-F_{2}(c) f_{1}(c)}{f_{1}(c)\left[f_{1}(c)+f_{2}(c)\right]}\right] d c\right. \\
& \left.+\int_{c_{L}}^{c_{H}} f_{2}(c)\left[1-(c+K)-\frac{F_{2}(c)}{f_{2}(c)}\right]\left[\frac{F_{2}(c) f_{1}(c)-F(c)_{1} f_{2}(c)}{f_{2}(c)\left[f_{1}(c)+f_{2}(c)\right]}\right] d c\right\} .
\end{aligned}
$$

Simplifying the above expression yields

$$
\Delta W=-\frac{1}{8} \int_{c_{L}}^{c_{H}} \frac{\left[F_{1}(c) f_{2}(c)-F_{2}(c) f_{1}(c)\right]^{2}}{f_{1}(c) f_{2}(c)\left[f_{1}(c)+f_{2}(c)\right]} d c<0
$$

which establishes the desired result.

\section{Proof of Proposition 9:}

The manufacturer maximizes

$$
\Pi=\alpha^{r}\left[t_{L}-k q_{L}\right]+\delta^{r}\left[t_{H}-k q_{H}\right]
$$

subject to $\left(\mathrm{IR}_{H}^{A}\right),\left(\mathrm{IC}_{H}\right),\left(\mathrm{IR}_{H}^{L}\right)$, and $\left(\mathrm{IC}_{L}\right)$. If discriminatory offers are allowed, then $\delta^{D}=$ $1-\alpha_{i}$ with regard to downstream firm $i \in\{1,2\}$. Under uniform wholesale tariffs, we have $\delta^{U}=2-\alpha_{\Sigma}$.

First, consider the relaxed optimization problem where, under pricing regime $r \in\{D, U\}$, $M$ maximizes (A.44) subject only to $\left(\mathrm{IR}_{H}^{A}\right)$ and $\left(\mathrm{IC}_{L}\right)$. For a given allocation $\left(q_{L}, q_{H}\right)$, the optimal transfers make both constrains bind:

$$
\begin{aligned}
t_{H}^{r} & =\pi\left(q_{H}, c_{H}\right)-\pi_{H}^{A}, \\
t_{L}^{r} & =\pi\left(q_{L}, c_{L}\right)-\pi\left(q_{H}, c_{L}\right)+\pi\left(q_{H}, c_{H}\right)-\pi_{H}^{A} .
\end{aligned}
$$

Except for being shifted downward by the amount $\pi_{H}^{A}$, the transfers are the same as in the standard case without alternative supply. In consequence, the optimal allocation is the same as in Section 4: $q_{L}^{r}\left(\alpha^{r}\right)=q^{J S}\left(c_{L}\right)$, and $q_{H}^{r}\left(\alpha^{r}\right)=\hat{q}^{r}\left(\alpha^{r}\right)$ for $\alpha^{r} \leq \hat{\alpha}^{r}$, where $\hat{\alpha}^{D}=\hat{\alpha}$ and $\hat{\alpha}^{U}=2 \hat{\alpha}$, and zero otherwise. With the allocation satisfying the monotonicity constraint (MON), $\left(\mathrm{IC}_{H}\right)$ is satisfied trivially because ( $\mathrm{IC}_{L}$ ) holds with equality. Thus, this allocation and the associated transfers solve $M$ 's original problem as long as the $\left(\mathrm{IR}_{L}^{A}\right)$ constraint is satisfied, or, equivalently, as long as

$$
\pi\left(q^{J S}\left(c_{L}\right), c_{L}\right)-t_{L}^{r} \geq \pi_{L}^{A} \Longleftrightarrow \phi \leq q_{H}^{r}\left(\alpha^{r}\right) .
$$

Recall that $\hat{q}^{r}\left(\alpha^{r}\right)$ is a strictly decreasing function with $\hat{q}^{r}(0)=q^{J S}\left(c_{H}\right)$ and $\hat{q}^{r}\left(\hat{\alpha}^{r}\right)=0$. In consequence, $\left(\operatorname{IR}_{L}^{A}\right)$ holds if $\phi \leq q^{J S}\left(c_{H}\right)$ and $\alpha^{r} \leq \alpha^{r}(\phi) \in\left[0, \hat{\alpha}^{r}\right]$, where $\alpha^{r}(\phi)$ is implicitly defined as

$$
q_{H}^{r}\left(\alpha^{r}(\phi)\right) \equiv \phi
$$


Existence and uniqueness of $\alpha^{r}(\phi)$ follow from the intermediate value theorem together with $\hat{q}^{r}\left(\alpha^{r}\right)$ being a continuous and strictly decreasing function on $\left[0, \hat{\alpha}^{r}\right]$.

Next, consider the relaxed problem where $M$ maximizes (A.44) subject only to ( $\operatorname{IR}_{H}^{A}$ ) and $\left(\operatorname{IR}_{L}^{A}\right)$. For a given allocation $\left(q_{L}, q_{H}\right)$, the optimal transfers make both constrains bind:

$$
\begin{aligned}
t_{L}^{r} & =\pi\left(q_{L}, c_{L}\right)-\pi_{L}^{A} \\
t_{H}^{r} & =\pi\left(q_{H}, c_{H}\right)-\pi_{H}^{A}
\end{aligned}
$$

Inserting these transfers into (A.44) reveals that $M$ 's goal is to maximize the joint surplus. Hence, the quantities implemented are $q_{L}^{r}\left(\alpha^{r}\right)=q^{J S}\left(c_{L}\right)$ and $q_{H}^{r}\left(\alpha^{r}\right)=q^{J S}\left(c_{H}\right)$. Obviously, the above wholesale mechanism satisfies the monotonicity constraint (MON). For this solution to the relaxed problem also to be a solution to the original problem, it needs to be checked that the mechanism is also incentive compatible. The incentive constraint of the low-cost firm, $\left(\mathrm{IC}_{L}\right)$, is satisfied if

$$
\pi\left(q^{J S}\left(c_{L}\right), c_{L}\right)-t_{L} \geq \pi\left(q^{J S}\left(c_{H}\right), c_{L}\right)-t_{H} \Longleftrightarrow q^{J S}\left(c_{H}\right) \leq \phi .
$$

A high-cost firm truthfully reveals its type, i.e. $\left(\mathrm{IC}_{H}\right)$ is satisfied, if

$$
\pi\left(q^{J S}\left(c_{H}\right), c_{H}\right)-t_{H} \geq \pi\left(q^{J S}\left(c_{L}\right), c_{H}\right)-t_{L} \Longleftrightarrow q^{J S}\left(c_{L}\right) \geq \phi .
$$

Thus, for $\phi \in\left[q^{J S}\left(c_{H}\right), q^{J S}\left(c_{L}\right)\right]$ the above wholesale mechanism is optimal under the original problem.

Last, consider the relaxed problem where $M$ maximizes (A.44) subject to $\left(\operatorname{IR}_{H}^{A}\right),\left(\operatorname{IR}_{L}^{A}\right)$, and $\left(\mathrm{IC}_{L}\right)$. For $\phi \leq q^{J S}\left(c_{H}\right)$ and $\alpha^{r} \leq \alpha^{r}(\phi)$, on the one hand, and for $\phi \in\left[q^{J S}\left(c_{H}\right), q^{J S}\left(c_{L}\right)\right]$, on the other hand, the solution to this problem is given by the solution to the respective less heavily constrained optimization problem considered before, where only two of the constraints were binding in the optimum. For $\phi<q^{J S}\left(c_{H}\right)$ and $\alpha^{r}>\alpha^{r}(\phi)$, however, in the optimum all three constraints must be binding. Thus, transfers under pricing regime $r \in\{D, U\}$ as functions of the implemented allocation $\left(q_{L}, q_{H}\right)$ are given by:

$$
\begin{aligned}
t_{H}^{r} & =\pi\left(q_{H}, c_{H}\right)-\pi_{H}^{A} \\
t_{L}^{r} & =\pi\left(q_{L}, c_{L}\right)-\pi_{L}^{A} \\
t_{L}^{r}-t_{H}^{r} & =\pi\left(q_{L}, c_{L}\right)-\pi\left(q_{H}, c_{L}\right) .
\end{aligned}
$$

Solving the above equations (A.51)-(A.53) for $q_{H}$ yields

$$
q_{H}^{r}\left(\alpha^{r}\right)=\frac{\pi_{L}^{A}-\pi_{H}^{A}}{c_{H}-c_{L}}=\phi .
$$

With $q_{H}$ being fixed by (A.54), $M$ chooses $q_{L}$ in order to maximize

$$
t_{L}^{r}-k q_{L}=\pi\left(q_{L}, c_{L}\right)-\pi_{L}^{A}-k q_{L}
$$

which is achieved by $q_{L}^{r}\left(\alpha^{r}\right)=q^{J S}\left(c_{L}\right)$. The above allocation clearly satisfies the monotonicity constraint $(\mathrm{MON})$, and $\left(\mathrm{IC}_{H}\right)$ trivially holds because $\left(\mathrm{IC}_{L}\right)$ is satisfied with equality. Thus, the above wholesale mechanism also is a solution to the original problem for $\phi<q^{J S}\left(c_{H}\right)$ and $\alpha^{r}>\alpha^{r}(\phi)$. This establishes the desired result. 


\section{Proof of Proposition 10:}

(i) For $\alpha_{2}<\alpha^{D}(\phi) \leq \alpha_{1}^{U}\left(\alpha_{2} ; \phi\right) \leq \alpha_{1}$, we have $q_{H 1}^{D}=q_{H}^{U}=\phi<q_{H 2}^{D}=\hat{q}^{D}\left(\alpha_{2}\right)$. According to (16), the difference in expected welfare amounts to

$$
\Delta W=\left(1-\alpha_{2}\right)\left\{\int_{\phi}^{\hat{q}^{D}\left(\alpha_{2}\right)} P(z) d z-\left(c_{H}+K\right)\left[\hat{q}^{D}\left(\alpha_{2}\right)-\phi\right]\right\}
$$

Thus, $\Delta W>0$ if and only if

$$
\int_{0}^{\hat{q}^{D}\left(\alpha_{2}\right)} P(z) d z-\left(c_{H}+K\right) \hat{q}^{D}\left(\alpha_{2}\right)>\int_{0}^{\phi} P(z) d z-\left(c_{H}+K\right) \phi .
$$

To see that this inequality indeed is satisfied, note that the function $\int_{0}^{q} P(z) d z-\left(c_{H}+K\right) q$ attains its maximum at $q^{*}$ which is implicitely characterized by $P\left(q^{*}\right)=c_{H}+K$. Comparing this last expression with the first-order condition characterizing $\hat{q}^{D}\left(\alpha_{2}\right)$ in (10) immediately implies $\hat{q}^{D}\left(\alpha_{2}\right)<q^{*}$. Since the function $\int_{0}^{q} P(z) d z-\left(c_{H}+K\right) q$ is strictly concave in $q$ whenever $P>0$, the result follows from $\phi<\hat{q}^{D}\left(\alpha_{2}\right)$.

(ii) If $\alpha_{2}<\alpha^{D}(\phi)<\alpha_{1}<\alpha_{1}^{U}\left(\alpha_{2} ; \phi\right)$, then $q_{H 1}^{D}=\phi<q_{H}^{U}=\hat{q}^{U}\left(\alpha_{\Sigma}\right)<q_{H 2}^{D}=\hat{q}^{D}\left(\alpha_{2}\right)$. The difference in expected welfare then is

$$
\begin{aligned}
\Delta W=\left(1-\alpha_{1}\right) & \left\{\int_{\hat{q}^{U}\left(\alpha_{\Sigma}\right)}^{\phi} P(z) d z-\left(c_{H}+K\right)\left[\phi-\hat{q}^{U}\left(\alpha_{\Sigma}\right)\right]\right\} \\
+ & \left(1-\alpha_{2}\right)\left\{\int_{\hat{q}^{U}\left(\alpha_{\Sigma}\right)}^{\hat{q}^{D}\left(\alpha_{2}\right)} P(z) d z-\left(c_{H}+K\right)\left[\hat{q}^{D}\left(\alpha_{2}\right)-\hat{q}^{U}\left(\alpha_{\Sigma}\right)\right]\right\} .
\end{aligned}
$$

Differentiation with respect to $\alpha_{1}$ yields

$$
\begin{aligned}
\frac{d \Delta W}{d \alpha_{1}}=-\left\{\int_{\hat{q}^{U}\left(\alpha_{\Sigma}\right)}^{\phi} P(z)\right. & \left.d z-\left(c_{H}+K\right)\left[\phi-\hat{q}^{U}\left(\alpha_{\Sigma}\right)\right]\right\} \\
& -\left(2-\left(\alpha_{1}+\alpha_{2}\right)\right) \frac{\hat{q}^{U}\left(\alpha_{\Sigma}\right)}{d \alpha_{1}}\left[P\left(\hat{q}^{U}\left(\alpha_{\Sigma}\right)\right)-\left(c_{H}+K\right)\right] .
\end{aligned}
$$

Note that $\phi<\hat{q}^{U}\left(\alpha_{\Sigma}\right)<q^{*}$, where $q^{*}$ was defined in the proof of part (i) and the second inequality follows from (14). The same reasoning as in the proof of part (i) implies $-\left\{\int_{\hat{q}^{U}\left(\alpha_{\Sigma}\right)}^{\phi} P(z) d z-\left(c_{H}+K\right)\left[\phi-\hat{q}^{U}\left(\alpha_{\Sigma}\right)\right]\right\}>0$. By (14) $P\left(\hat{q}^{U}\left(\alpha_{\Sigma}\right)\right)-\left(c_{H}+K\right)=$ $P^{\prime}\left(\hat{q}^{U}\left(\alpha_{\Sigma}\right)\right) \hat{q}^{U}\left(\alpha_{\Sigma}\right)+\frac{\alpha_{\Sigma}}{2-\alpha_{\Sigma}}\left(c_{H}-c_{L}\right)>0$, and the desired result follows from $d \hat{q}^{U}\left(\alpha_{\Sigma}\right) / d \alpha_{1}<$ 0 .

(iii) Follows immediately from the proof of Proposition 4.

\section{REFERENCES}

Aguirre, I., S. Cowan, AND J. Vickers (2010): “Monopoly Price Discrimination and Demand Curvature," American Economic Review, 100, 1601-1615.

ARYA, A., AND B. MitTEndorf (2010): "Input Price Discrimination When Buyers Operate in Multiple Markets," Journal of Industrial Economics, 58, 846-867.

Bonnet, C., AND P. Dubois (2010): "Inference on Vertical Contracts between Manufacturers and Retailers allowing for Nonlinear Pricing and Resale Price Maintenance," RAND Journal of Economics, 41, 139-164.

Bork, R. (1978): The Antitrust Paradox. Basic Books, New York. 
CAPRICE, S. (2006): "Multilateral Vertical Contracting with an Alternative Supply: The Welfare Effects of a Ban on Price Discrimination," Review of Industrial Organization, 28, 63-80.

DeGraba, P. (1990): "Input Market Price Discrimination and the Choice of Technology," American Economic Review, 80, 1246-1253.

DiXIT, A. (1979): "A Model of Duopoly Suggesting a Theory of Entry Barriers," Bell Journal of Economics, 10, $20-32$.

Geradin, D., AND N. Petit (2005): "Price Discrimination under EC Competition Law: The Need for a Caseby-Case Approach," GCLC Working Paper 07/05.

Giardino-Karlinger, L., AND M. MotTA (forthcoming): "Exclusionary Pricing When Scale Matters," Journal of Industrial Economics.

Herweg, F., AND D. MÜLleR (forthcoming): "Price Discrimination in Input Markets: Downstream Entry and Efficiency," Journal of Economics and Management Strategy.

Inderst, R., AND G. ShafFer (2009): "Market Power, Price Discrimination, and Allocative Efficiency in Intermediate-Good Markets," RAND Journal of Economics, 40, 658-672.

Inderst, R., AND T. VALletti (2009): "Price Discrimination in Input Markets," RAND Journal of Economics, 40, 1-19.

JulLiEn, B. (1996): "L'impact des options extérieures sur les échanges en information asymétrique," Revue économique, 47, 437-446.

(2000): "Participation Constraints in Adverse Selection Models," Journal of Economic Theory, 93, 1-47.

KATZ, M. L. (1987): "The Welfare Effects of Third-Degree Price Discrimination in Intermediate Good Markets," American Economic Review, 77, 154-167.

LAfFont, J. J., AND D. MARTIMort (2002): The Theory of Incentives. Princeton Press, Princeton.

LEWIS, T., AND D. E. M. SAPPIngton (1989): “Countervailing Incentives in Agency Problems," Journal of Economic Theory, 49, 294-313.

Luchs, R., T. Geylani, A. Dukes, And K. SRinivasan (2010): "The End of the Robinson-Patman Act? Evidence from Legal Case Data," Management Science, 56, 2123-2133.

Malueg, D. (1993): "Bounding the Welfare Effects of Third-Degree Price Discrimination," American Economic Review, 83, 1011-1021.

O'BRIEN, D. P. (forthcoming): “The Welfare Effects of Third-Degree Price Discrimination in Intermediate Good Markets: The Case of Bargaining," RAND Journal of Economics.

O'Brien, D. P., AND G. Shaffer (1994): “The Welfare Effects of Forbidding Discriminatory Discounts: A Secondary-Line Analysis of Robinson-Patman," Journal of Law, Economics, and Organization, 10, 296-318.

Rey, P., AND J. Tirole (1986): “The Logic of Vertical Restraints,” American Economic Review, 76, 921-939. (2007): “A Primer on Foreclosure," in Handbook of Industrial Organization 3, ed. by M. Armstrong, and R. Porter, pp. 2145-2220, Amsterdam, Elsevier. University of California Press.

Russo, F., M. P. Schinkel, A. GÜnster, AND M. CARree (2010): European Commission Decisions on Competition, Economic Perspectives on Landmark Antitrust and Merger Cases. Cambridge University Press, Cambridge.

SCHMALENSEE, R. (1981): "Output and Welfare Implications of Monopolistic Third-Degree Price Discrimination," American Economic Review, 71, 242-247.

SChWARTZ, M. (1990): "Third-Degree Price Discrimination and Output: Generalizing a Welfare Result," American Economic Review, 80, 1259-1262.

Singh, N., AND X. VIVES (1984): "Price and Quantity Competition in a Differentiated Duopoly," RAND Journal of Economics, 15, 546-554.

TIROLE, J. (1988): The Theory of Industrial Organization. MIT Press, Cambridge.

Valletti, T. (2003): "Input Price Discrimination with Downstream Cournot Competitors," International Journal of Industrial Organization, 21, 969-988.

VARIAN, H. (1985): "Price Discrimination and Social Welfare," American Economic Review, 75, 870-875.

VILLAS-BOAS, S. B. (2007): "Vertical Relationships between Manufacturers and Retailers: Inference with Limited Data," Review of Economic Studies, 74, 625-652.

Vives, X. (1999): Oligopoly Pricing: Old Ideas and New Tools. MIT Press, Cambridge.

Waelbroek, D. (2005): "Michelin II: A Per Se Rule Against Rebates by Dominant Companies?, Journal of Competition Law and Economics, 1, 149-171.

YoshidA, Y. (2000): “Third-Degree Price Discrimination in Input Market: Output and Welfare," American Economic Reviews, 90, 240-246. 


\section{B. Supplementary Material (NOT FOR Publication)}

\section{Supplementary Material for Section 7}

\section{Proof of Lemma 5:}

In what follows, we continue to make use of the following: $q_{i}^{J S}=q^{J S}\left(c_{i}\right)=\left(1-c_{i}-K\right) / 2$; Note, however, that $q_{i}^{J S}$ does not refer to the joint-surplus maximizing quantity in the context of downstream competition.

With transfers charged to firm $i$ being pinned down by $\left(\mathrm{IR}_{i H}\right)$ and $\left(\mathrm{IC}_{i L}\right), M$ chooses quantities in order to solve

$$
\begin{aligned}
\underset{q_{1 L}, q_{1 H}, q_{2 L}, q_{2 H}}{\max } \Pi^{D}= & \alpha_{1}\left\{q_{1 L}\left[1-q_{1 L}-\gamma E_{2}[q]-c_{L}\right]-q_{1 L}\left(c_{H}-c_{L}\right)-K q_{1 L}\right\} \\
& \left(1-\alpha_{1}\right)\left\{q_{1 H}\left[1-q_{1 H}-\gamma E_{2}[q]-c_{H}\right]-K q_{1 H}\right\} \\
& \alpha_{2}\left\{q_{2 L}\left[1-q_{2 L}-\gamma E_{1}[q]-c_{L}\right]-q_{2 L}\left(c_{H}-c_{L}\right)-K q_{2 L}\right\} \\
& \left(1-\alpha_{2}\right)\left\{q_{2 H}\left[1-q_{2 H}-\gamma E_{1}[q]-c_{H}\right]-K q_{2 H}\right\}
\end{aligned}
$$

The necessary F.O.C.s read:

$$
\frac{\partial \Pi^{D}}{\partial q_{i L}}=0 \Rightarrow q_{i L}=q^{J S}\left(c_{L}\right)-\gamma E_{j}[q]
$$

and

$$
\frac{\partial \Pi^{D}}{\partial q_{i H}}=0 \Rightarrow q_{i H}=q^{J S}\left(c_{H}\right)-\gamma E_{j}[q]-\frac{\alpha_{i}}{1-\alpha_{i}} \frac{c_{H}-c_{L}}{2}
$$

where $i \neq j$. With $E\left[q_{i}\right]=\alpha_{i} q_{i L}+\left(1-\alpha_{i}\right) q_{i H}$, combining (B.2) and (B.3) yields

$$
E_{i}[q]=E_{j}[q]=\frac{q^{J S}}{1+\gamma}
$$

Plugging (B.4) back into (B.2) and (B.3) allows us to solve for

$$
q_{i L}^{D}(\gamma)=q_{L}^{J S}-\frac{\gamma}{1+\gamma} q_{H}^{J S} \quad \text { and } \quad q_{i H}^{D}(\gamma)=\frac{1}{1+\gamma} q_{H}^{J S}-\frac{\alpha_{i}}{1-\alpha_{i}} \frac{c_{H}-c_{L}}{2} .
$$

In order to show that the above F.O.C.s are not only necessary but also sufficient, consider the associated Hessian mtrix of second-order derivatives:

$$
\begin{gathered}
\boldsymbol{H}^{D}=\left(\begin{array}{cccc}
\frac{\partial^{2} \Pi^{D}}{\partial q_{1 L}^{2}} & \frac{\partial^{2} \Pi^{D}}{\partial q_{1 L} \partial q_{1 H}} & \frac{\partial^{2} \Pi^{D}}{\partial q_{1 L} \partial q_{2 L}} & \frac{\partial^{2} \Pi^{D}}{\partial q_{1 L} \partial q_{2 H}} \\
\frac{\partial^{2} \Pi^{D}}{\partial q_{1 H} \partial q_{1 L}} & \frac{\partial^{2} \Pi^{D}}{\partial q_{1 H}^{2}} & \frac{\partial^{2} \Pi^{D}}{\partial q_{1 H} \partial q_{2 L}} & \frac{\partial^{2} \Pi^{D}}{\partial q_{1 H} \partial q_{2 H}} \\
\frac{\partial^{2} \Pi^{D}}{\partial q_{2 L} \partial q_{1 L}} & \frac{\partial^{2} \Pi^{D}}{\partial q_{2 L} \partial q_{1 H}} & \frac{\partial^{2} \Pi^{D}}{\partial q_{2 L}^{2}} & \frac{\partial^{2} \Pi^{D}}{\partial q_{2 L} \partial q_{2 H}} \\
\frac{\partial^{2} \Pi^{D}}{\partial q_{2 H} \partial q_{1 L}} & \frac{\partial^{2} \Pi^{D}}{\partial q_{2 H} \partial q_{1 H}} & \frac{\partial^{2} \Pi^{D}}{\partial q_{2 H} \partial q_{2 L}} & \frac{\partial^{2} \Pi^{D}}{\partial q_{2 H}^{2}}
\end{array}\right) \\
=\left(\begin{array}{cccc}
-2 \alpha_{1} & 0 & -2 \gamma \alpha_{1} \alpha_{2} & -2 \gamma \alpha_{1}\left(1-\alpha_{2}\right) \\
0 & -2\left(1-\alpha_{1}\right) & -2 \gamma\left(1-\alpha_{1}\right) \alpha_{2} & -2 \gamma\left(1-\alpha_{1}\right)\left(1-\alpha_{2}\right) \\
-2 \gamma \alpha_{1} \alpha_{2} & -2 \gamma\left(1-\alpha_{1}\right) \alpha_{2} & -2 \alpha_{2} & 0 \\
-2 \gamma \alpha_{1}\left(1-\alpha_{2}\right) & -2 \gamma\left(1-\alpha_{1}\right)\left(1-\alpha_{2}\right) & 0 & -2\left(1-\alpha_{2}\right)
\end{array}\right)
\end{gathered}
$$


Letting $D_{k}$ denote the $k$ th leading principal minor, we have

$$
\begin{aligned}
& (-1)^{1} \boldsymbol{D}_{1}=2 \alpha_{1}>0 \\
& (-1)^{2} \boldsymbol{D}_{2}=4 \alpha_{1}\left(1-\alpha_{1}\right)>0 \\
& (-1)^{3} \boldsymbol{D}_{3}=8 \alpha_{1} \alpha_{2}\left(1-\alpha_{1}\right)\left(1-\gamma^{2} \alpha_{2}\right)>0 \\
& (-1)^{4} \boldsymbol{D}_{4}=16 \alpha_{1} \alpha_{2}\left(1-\alpha_{1}\right)\left(1-\alpha_{2}\right)\left(1-\gamma^{2}\right)>0
\end{aligned}
$$

such that the objective function is strictly concave and the F.O.C.s are indeed sufficient for optimality.

From (B.5) it follows immediately that the monotonicity requirement imposed by incentive compatibility is satisfied:

$$
q_{i L}^{D}(\gamma)>q_{i H}^{D}(\gamma) \Longleftrightarrow q_{L}^{J S}>q_{H}^{J S}-\frac{\alpha_{i}}{1-\alpha_{i}} .
$$

Next, we show that $M$ wants to serve both firms for $\gamma$ sufficiently low:

$$
q_{i H}^{D}(\gamma)>0 \Longleftrightarrow \gamma<\frac{\left(1-c_{H}-K\right)-\alpha_{i}\left(1-c_{L}-K\right)}{c_{H}-c_{L}}=: \gamma_{>0}^{D},
$$

where $\left(1-c_{H}-K\right)-\alpha_{i}\left(1-c_{L}-K\right)>0$ since $\alpha_{i}<\hat{\alpha}^{D}$.

Last, it remains to argue that free disposal has no bite for $\gamma$ sufficiently low. Given quantity $q_{j}$, firm $i^{\prime} s$ best response is given by

$$
q_{i}\left(q_{j} \mid c_{i}\right)=\arg \max _{q} q\left(1-q-\gamma q_{j}-c_{i}\right)=\frac{1-c_{i}}{2}-\frac{\gamma}{2} q_{j} .
$$

With firm $i$ 's best response being decreasing in firm $j$ 's quantity, for free disposal not to impose a binding restriction we must have $q_{i H}^{D}(\gamma) \leq q_{i}\left(q_{j L}^{D}(\gamma) \mid c_{i}\right)$ and $q_{i L}^{D}(\gamma) \leq q_{i}\left(q_{j L}^{D}(\gamma) \mid c_{i}\right)$. First, note that $q_{i H}^{D}(\gamma) \leq q_{i}\left(q_{j L}^{D}(\gamma) \mid c_{H}\right)$ if and only if

$$
\begin{aligned}
\gamma^{2}\left(c_{H}-c_{L}\right)+\gamma\left[q^{J S}\left(c_{L}\right)-\frac{\alpha_{i}}{1-\alpha_{i}}\left(c_{H}-c_{L}\right)\right. & \left.-\left(1-c_{H}\right)\right] \\
& -\left[K+\frac{\alpha_{i}}{1-\alpha_{i}}\left(c_{H}-c_{L}\right)\right] \leq 0 .
\end{aligned}
$$

The quadratic function on the LHS of (B.13) has two zeros, one of which is strictly positive, whereas the other one is strictly negative. In consequence, (B.13) is satisfied for all $\gamma \in\left[0, \gamma_{F H}^{D}\right]$, where

$$
\begin{aligned}
\gamma_{F H}^{D} & :=\frac{\left(1-c_{H}\right)-q^{J S}\left(c_{L}\right)+\frac{\alpha_{i}}{1-\alpha_{i}}\left(c_{H}-c_{L}\right)}{2\left(c_{H}-c_{L}\right)} \\
& +\sqrt{\left[\frac{\left(1-c_{H}\right)-q^{J S}\left(c_{L}\right)+\frac{\alpha_{i}}{1-\alpha_{i}}\left(c_{H}-c_{L}\right)}{2\left(c_{H}-c_{L}\right)}\right]^{2}+\left[K+\frac{\alpha_{i}}{1-\alpha_{i}}\left(c_{H}-c_{L}\right)\right]} .
\end{aligned}
$$

Likewise, $q_{i L}^{D}(\gamma) \leq q_{i}\left(q_{j L}^{D}(\gamma) \mid c_{L}\right)$ if and only if

$$
\gamma^{2}\left(c_{H}-c_{L}\right)+\gamma\left[q^{J S}\left(c_{L}\right)+2\left(c_{H}-c_{L}\right)-\left(1-c_{L}\right)\right]-K \leq 0 .
$$


The quadratic function on the LHS of (B.15) has two zeros, one of which is strictly positive, whereas the other one is strictly negative. In consequence, (B.15) is satisfied for all $\gamma \in\left[0, \gamma_{F L}^{D}\right]$, where

$$
\begin{aligned}
& \gamma_{F L}^{D}:=\frac{1-c_{L}-q^{J S}\left(c_{L}\right)-2\left(c_{H}-c_{L}\right)}{2\left(c_{H}-c_{L}\right)} \\
&+\sqrt{\left[\frac{1-c_{L}-q^{J S}\left(c_{L}\right)-2\left(c_{H}-c_{L}\right)}{2\left(c_{H}-c_{L}\right)}\right]^{2}+\frac{K}{c_{H}-c_{L}}}
\end{aligned}
$$

Defining $\gamma^{D}:=\min \left\{\gamma_{>0}^{D}, \gamma_{F H}^{D}, \gamma_{F L}^{D}\right\}$ establishes the desired result.

\section{Proof of Lemma 6:}

In what follows, we continue to make use of the following: $q_{i}^{J S}=q^{J S}\left(c_{i}\right)=\left(1-c_{i}-K\right) / 2$; Note, however, that $q_{i}^{J S}$ does not refer to the joint-surplus maximizing quantity in the context of downstream competition.

As we argued in the text, if $\left(\mathrm{IR}_{2 H}\right)$ and $\left(\mathrm{IC}_{2 L}\right)$ are both satisfied with equality, then-with exception of $\left(\mathrm{IC}_{1 H}\right)$-all remaining incentive compatibility and individual rationality constraints are automatically satisfied. For the moment, we therefore ignore $\left(\mathrm{IC}_{1 H}\right)$ and show that this constraint is satisfied as well under the optimal contract for $\gamma$ sufficiently small.

With transfers being determined by $\left(\mathrm{IR}_{2 H}\right)$ and $\left(\mathrm{IC}_{2 L}\right), M$ chooses quantities in order to solve

$$
\begin{aligned}
\max _{q_{L}, q_{H}} \Pi^{U}= & \alpha_{\Sigma}\left\{q_{L}\left[1-q_{L}-\gamma E_{1}[q]-c_{L}\right]-q_{L}\left(c_{H}-c_{L}\right)-K q_{L}\right\} \\
& +\left(2-\alpha_{\Sigma}\right)\left\{q_{H}\left[1-q_{H}-\gamma E_{1}[q]-c_{H}\right]-K q_{H}\right\}
\end{aligned}
$$

The necessary F.O.C.s read:

$$
\frac{\partial \Pi^{U}}{\partial q_{L}}=0 \Rightarrow q_{L}=q^{J S}\left(c_{L}\right) \frac{1}{1+\gamma \alpha_{1}}-\gamma \frac{\alpha_{\Sigma}\left(1-\alpha_{1}\right)+\left(2-\alpha_{\Sigma}\right) \alpha_{1}}{2 \alpha_{\Sigma}\left(1+\gamma \alpha_{1}\right)} q_{H},
$$

and

$$
\begin{aligned}
\frac{\partial \Pi^{U}}{\partial q_{H}}=0 \Rightarrow q_{i H}=q^{J S}\left(c_{H}\right) & \frac{1}{1+\gamma\left(1-\alpha_{1}\right)} \\
-\frac{\alpha_{\Sigma}}{2-\alpha_{\Sigma}} \frac{c_{H}-c_{L}}{2} & \frac{1}{1+\gamma\left(1-\alpha_{1}\right)} \\
& \quad-\gamma \frac{\alpha_{\Sigma}\left(1-\alpha_{1}\right)+\left(2-\alpha_{\Sigma}\right) \alpha_{1}}{2\left(2-\alpha_{\Sigma}\right)\left(1+\gamma\left(1-\alpha_{1}\right)\right)} q_{L} .
\end{aligned}
$$

Rearranging these F.O.C.s yields

$$
\begin{aligned}
q_{L}^{U}(\gamma)= & q^{J S}\left(c_{L}\right) \frac{4 \alpha_{\Sigma}\left(2-\alpha_{\Sigma}\right)\left(1+\gamma\left(1-\alpha_{1}\right)\right)}{\Lambda(\gamma)} \\
& -\gamma \frac{\left[\alpha_{\Sigma}\left(1-\alpha_{1}\right)+\left(2-\alpha_{\Sigma}\right) \alpha_{1}\right]\left[\left(2-\alpha_{\Sigma}\right)\left(1-c_{H}-K\right)-\alpha_{\Sigma}\left(c_{H}-c_{L}\right)\right]}{\Lambda(\gamma)}
\end{aligned}
$$

and

$$
\begin{gathered}
q_{H}^{U}(\gamma)=q^{J S}\left(c_{H}\right) \frac{4 \alpha_{\Sigma}\left(2-\alpha_{\Sigma}\right)\left(1+\gamma \alpha_{1}\right)}{\Lambda(\gamma)}-\left(c_{H}-c_{L}\right) \frac{2\left(\alpha_{\Sigma}\right)^{2}\left(1+\gamma \alpha_{1}\right)}{\Lambda(\gamma)} \\
-\gamma \frac{\left[\alpha_{\Sigma}\left(1-\alpha_{1}\right)+\left(2-\alpha_{\Sigma}\right) \alpha_{1}\right] \alpha_{\Sigma}\left(1-c_{L}-K\right)}{\Lambda(\gamma)}
\end{gathered}
$$


where

$$
\Lambda(\gamma)=4 \alpha_{\Sigma}\left(2-\alpha_{\Sigma}\right)(1+\gamma)-\gamma^{2}\left(\alpha_{\Sigma}-2 \alpha_{1}\right)^{2}
$$

In order to guarantee that $M$ 's problem is well behaved, consider the Hessian matrix

$$
\begin{aligned}
\boldsymbol{H}^{U} & =\left(\begin{array}{cc}
\frac{\partial^{2} \Pi^{U}}{\partial q_{L}^{2}} & \frac{\partial^{2} \Pi^{U}}{\partial q_{L} \partial q_{H}} \\
\frac{\partial^{2} \Pi^{U}}{\partial q_{H} \partial q_{L}} & \frac{\partial^{2} \Pi^{U}}{\partial q_{H}^{2}}
\end{array}\right) \\
& =\left(\begin{array}{cc}
-2 \alpha_{\Sigma}\left(1+\gamma \alpha_{1}\right) & -\gamma\left[\alpha_{\Sigma}\left(1-\alpha_{1}\right)+\left(2-\alpha_{\Sigma}\right) \alpha_{1}\right] \\
-\gamma\left[\alpha_{\Sigma}\left(1-\alpha_{1}\right)+\left(2-\alpha_{\Sigma}\right) \alpha_{1}\right] & -2\left(2-\alpha_{\Sigma}\right)\left(1+\gamma\left(1-\alpha_{1}\right)\right)
\end{array}\right)
\end{aligned}
$$

It is readily verified that $\left|H^{U}\right|>0$ if and only if $\Lambda(\gamma)>0$. In consequence, $M$ 's objective function is strictly concave for $\gamma \in\left[0, \gamma_{c}^{U}\right)$, where

$$
\gamma_{c}^{U}:=\frac{2 \alpha_{\Sigma}\left(2-\alpha_{\Sigma}\right)}{\left(\alpha_{\Sigma}-2 \alpha_{1}\right)^{2}}+\sqrt{\left(\frac{2 \alpha_{\Sigma}\left(2-\alpha_{\Sigma}\right)}{\left(\alpha_{\Sigma}-2 \alpha_{1}\right)^{2}}\right)^{2}+\frac{4 \alpha_{\Sigma}\left(2-\alpha_{\Sigma}\right)}{\left(\alpha_{\Sigma}-2 \alpha_{1}\right)^{2}}} .
$$

Focusing on the case where $\Lambda(\gamma)>0$, we next show that $0<q_{H}^{U}<q_{L}^{U}$ is satisfied for $\gamma$ sufficiently small. First, we have $q_{H}^{U}>0$ if and only if

$$
\gamma \Omega<2 \alpha_{\Sigma}\left[2\left(1-c_{H}-K\right)-\alpha_{\Sigma}\left(1-c_{L}-K\right)\right]
$$

where

$$
\begin{aligned}
\Omega:=\left[\alpha_{\Sigma}\left(1-\alpha_{1}\right)+(2-\right. & \left.\left.\alpha_{\Sigma}\right) \alpha_{1}\right] \alpha_{\Sigma}\left(1-c_{L}-K\right) \\
& -\left(1-c_{H}-K\right) 2 \alpha_{\Sigma} \alpha_{1}\left(2-\alpha_{\Sigma}\right)+2\left(\alpha_{\Sigma}\right)^{2} \alpha_{1}\left(c_{H}-c_{L}\right) .
\end{aligned}
$$

Since the RHS of (B.24) is strictly positive for $\alpha_{1}<\hat{\alpha}^{D}$, (B.24) is satisfied for $\gamma \in\left[0, \gamma_{0<H}^{U}\right)$, where $\gamma_{0<H}^{U}$ is defined as follows: $\gamma_{0<H}^{U}=1$ if $\Omega \leq 0$ and

$$
\gamma_{0<H}^{U}:=\frac{2 \alpha_{\Sigma}\left[2\left(1-c_{H}-K\right)-\alpha_{\Sigma}\left(1-c_{L}-K\right)\right]}{\Omega}
$$

if $\Omega>0$.

Likewise, $q_{H}^{U}<q_{L}^{U}$ if and only if

$$
\gamma \hat{\Omega}>-4 \alpha_{\Sigma}\left(c_{H}-c_{L}\right)
$$

where

$$
\hat{\Omega}:=4 \alpha_{\Sigma}\left(1-c_{H}-K\right)-\left[2-\alpha_{\Sigma}+2\left(\alpha_{\Sigma}-2 \alpha_{1}\right)\right]\left(1-c_{H}-K\right)
$$

Thus, (B.26) is satisfied for $\gamma \in\left[0, \gamma_{H<L}^{U}\right)$, where $\gamma_{H<L}^{U}$ is defined as follows: $\gamma_{H<L}^{U}=1$ if $\hat{\Omega} \geq 0$ and

$$
\gamma_{H<L}^{U}:=\frac{4 \alpha_{\Sigma}\left(c_{H}-c_{L}\right)}{\left|4 \alpha_{\Sigma}\left(1-c_{H}-K\right)-\left[2-\alpha_{\Sigma}+2\left(\alpha_{\Sigma}-2 \alpha_{1}\right)\right]\left(1-c_{H}-K\right)\right|} .
$$

if $\hat{\Omega}<0$. 
We still to check that free disposal does not impose a binding restriction. First, note that $q_{H}^{U}(\gamma) \leq q_{i}\left(q_{L}^{U}(\gamma) \mid c_{H}\right)$ if and only if

$$
\gamma^{2} A_{F H}+\gamma B_{F H}+C_{F H} \leq 0
$$

where

$$
\begin{gathered}
A_{F H}=\left(1-c_{L}-K\right) 2 \alpha_{\Sigma}\left(2-\alpha_{\Sigma}\right)\left(1-\alpha_{1}\right)+\left(\alpha_{\Sigma}-2 \alpha_{1}\right)^{2}\left(1-c_{H}\right) \\
-\left[\alpha_{\Sigma}\left(1-\alpha_{1}\right)+\left(2-\alpha_{\Sigma}\right) \alpha_{1}\right]\left\{\left(2-\alpha_{\Sigma}\right)\left(1-c_{H}-K\right)-\alpha_{\Sigma}\left(c_{H}-c_{L}\right)\right\} \\
B_{F H}=4\left(1-c_{H}-K\right) \alpha_{\Sigma}\left(2-\alpha_{\Sigma}\right) \alpha_{1}-4\left(\alpha_{\Sigma}\right)^{2}\left(c_{H}-c_{L}\right) \alpha_{1} \\
-2\left[\alpha_{\Sigma}\left(1-\alpha_{1}\right)+\left(2-\alpha_{\Sigma}\right) \alpha_{1}\right] \alpha_{\Sigma}\left(1-c_{L}-k\right) \\
+\left(1-c_{L}-k\right) 2 \alpha_{\Sigma}\left(2-\alpha_{\Sigma}\right)-\left(1-c_{H}\right) 4 \alpha_{\Sigma}\left(2-\alpha_{\Sigma}\right), \\
C_{F H}=-4 \alpha_{\Sigma}\left[K\left(2-\alpha_{\Sigma}\right)+\alpha_{\Sigma}\left(c_{H}-c_{L}\right)\right]<0 .
\end{gathered}
$$

\section{Defining}

$$
\gamma_{F H}^{U}=\left\{\begin{array}{cll}
-\frac{B_{F H}}{2 A_{F H}}+\sqrt{\left(\frac{B_{F H}}{2 A_{F H}}\right)^{2}-\frac{C_{F H}}{A_{F H}}} & \text { if } & A_{F H}>0 \\
-\frac{B_{F H}}{2 A_{F H}}-\sqrt{\left(\frac{B_{F H}}{2 A_{F H}}\right)^{2}-\frac{C_{F H}}{A_{F H}}} & \text { if } & A_{F H}<0, B_{F H}>0 \text { and }\left(\frac{B_{F H}}{2 A_{F H}}\right)^{2} \geq \frac{C_{F H}}{A_{F H}} \\
-\frac{C_{F H}}{B_{F H}} & \text { if } & A_{F H}=0, B_{F H}>0 \\
1 & \text { otherwise }
\end{array}\right.
$$

(B.30) is satisfied at for $\gamma \in\left[0, \gamma_{F H}^{U}\right)$. Likewise, $q_{L}^{U}(\gamma) \leq q_{i}\left(q_{L}^{U}(\gamma) \mid c_{L}\right)$ if and only if

$$
\gamma^{2} A_{F L}+\gamma B_{F L}+C_{F L} \leq 0,
$$

where

$$
\begin{gathered}
A_{F L}=\left(1-c_{L}\right)\left(\alpha_{\Sigma}-2 \alpha_{1}\right)^{2}+\left(1-c_{L}-K\right) 2 \alpha_{\Sigma}\left(2-\alpha_{\Sigma}\right)\left(1-\alpha_{1}\right) \\
-\left[\alpha_{\Sigma}\left(1-\alpha_{1}\right)+\left(2-\alpha_{\Sigma}\right) \alpha_{1}\right]\left\{\left(2-\alpha_{\Sigma}\right)\left(1-c_{H}-K\right)-\alpha_{\Sigma}\left(c_{H}-c_{L}\right)\right\} \\
B_{F L}=\left(1-c_{L}-K\right) 2 \alpha_{\Sigma}\left(2-\alpha_{\Sigma}\right)+4\left(1-c_{L}-K\right) \alpha_{\Sigma}\left(2-\alpha_{\Sigma}\right)\left(1-\alpha_{1}\right) \\
-2\left[\alpha_{\Sigma}\left(1-\alpha_{1}\right)+\left(2-\alpha_{\Sigma}\right) \alpha_{1}\right]\left\{\left(2-\alpha_{\Sigma}\right)\left(1-c_{H}-K\right)-\alpha_{\Sigma}\left(c_{H}-{ }_{L}\right)\right\} \\
-\left(1-c_{L}\right) 4 \alpha_{\Sigma}\left(2-\alpha_{\Sigma}\right), \\
C_{F L}=-4 \alpha_{\Sigma}\left(2-\alpha_{\Sigma}\right) K<0 .
\end{gathered}
$$

Defining

$$
\gamma_{F L}^{U}=\left\{\begin{array}{cll}
-\frac{B_{F L}}{2 A_{F L}}+\sqrt{\left(\frac{B_{F L}}{2 A_{F L}}\right)^{2}-\frac{C_{F L}}{A_{F L}}} & \text { if } & A_{F L}>0 \\
-\frac{B_{F L}}{2 A_{F L}}-\sqrt{\left(\frac{B_{F L}}{2 A_{F L}}\right)^{2}-\frac{C_{F L}}{A_{F L}}} & \text { if } & A_{F L}<0, B_{F L}>0 \text { and }\left(\frac{B_{F L}}{2 A_{F L}}\right)^{2} \geq \frac{C_{F L}}{A_{F L}} \\
-\frac{C_{F L}}{B_{F L}} & \text { if } & A_{F L}=0, B_{F L}>0 \\
1 & \text { otherwise }
\end{array}\right.
$$


(B.35) is satisfied at for $\gamma \in\left[0, \gamma_{F L}^{U}\right)$.

It remains to show that $\left(\mathrm{IC}_{1 H}\right)$ is satisfied for $\gamma$ sufficiently small if transfers are chosen such that $\left(\mathrm{IC}_{2 L}\right)$ just binds, i.e.,

$$
\begin{aligned}
& q_{L}^{U}\left[1-q_{L}^{U}-E_{1}\left[q^{U}\right]-c_{L}\right]-q_{H}^{U}\left[1-q_{H}^{U}-E_{1}\left[q^{U}\right]-c_{L}\right]=t_{L}-t_{H} \\
& \geq q_{L}^{U}\left[1-q_{L}^{U}-E_{1}\left[q^{U}\right]-c_{H}\right]-q_{H}\left[1-q_{H}^{U}-E_{1}\left[q^{U}\right]-c_{H}\right] .
\end{aligned}
$$

Using the fact that the monotonicity requirement is satisfied for $\gamma$ sufficiently small, $q_{L}^{U} \geq q_{H}^{U}$, and that $\alpha_{1}-\alpha_{2}=2 \alpha_{1}-\alpha_{\Sigma}$, the above condition can be rewritten as

$$
\gamma\left(2 \alpha_{1}-\alpha_{\Sigma}\right)\left(q_{L}^{U}-q_{H}^{U}\right) \leq\left(c_{H}-c_{L}\right)
$$

Substituting (B.20) and (B.21) into (B.41) and (straightforward but nevertheless very tedious) rearranging results in the following equivalent condition:

$$
\gamma^{2} \tilde{\Omega} \leq\left(c_{H}-c_{L}\right) 4 \alpha_{\Sigma}\left(2-\alpha_{\Sigma}\right)+\gamma\left(c_{H}-c_{L}\right) 4 \alpha_{\Sigma} 2\left(1-\alpha_{1}\right),
$$

where

$$
\tilde{\Omega}:=\left(2 \alpha_{1}-\alpha_{\Sigma}\right)\left\{\left(1-c_{L}-K\right) \alpha_{\Sigma} 4-2\left(\alpha_{\Sigma}+2 \alpha_{1}\right)\left(1-c_{H}-K\right)+\left(c_{H}-c_{L}\right)\left(2 \alpha_{1}-\alpha_{\Sigma}\right)\right\} .
$$

Note that the RHS of (B.42) is strictly positive. Thus, $\left(\mathrm{IC}_{1 H}\right)$ is satisfied if $\left(\mathrm{IC}_{2 L}\right)$ binds for $\gamma \in\left[0, \gamma_{I C 1 H}\right)$, where $\gamma_{I C 1 H}$ is defined as follows: $\gamma_{I C 1 H}=1$ if $\tilde{\Omega} \leq 0$, and

$$
\begin{aligned}
\gamma_{I C 1 H}=\frac{\left(c_{H}-c_{L}\right) 4 \alpha_{\Sigma} 2\left(1-\alpha_{1}\right)}{2 \tilde{\Omega}} & \\
& +\sqrt{\left(\frac{\left(c_{H}-c_{L}\right) 4 \alpha_{\Sigma} 2\left(1-\alpha_{1}\right)}{2 \tilde{\Omega}}\right)^{2}+\frac{\left(c_{H}-c_{L}\right) 4 \alpha_{\Sigma}\left(2-\alpha_{\Sigma}\right)}{\tilde{\Omega}}} .
\end{aligned}
$$

if $\tilde{\Omega}>0$.

Defining $\gamma^{U}:=\min \left\{\gamma_{c}^{U}, \gamma_{0<H}^{U}, \gamma_{H<L}^{U}, \gamma_{F H}^{U}, \gamma_{F L}^{U}, \gamma_{I C 1 H}^{U}\right\}$ establishes the desired result.

\section{Supplementary Material for Section 8}

To complement the analysis in Section 8, we now give a detailed account for under what circumstances the upstream firm prefers to serve only one type of downstream firm. Unless stated otherwise, the following observations apply to both pricing regimes.

Clearly, when serving only one type of downstream firm with cost $c$, the highest possible profit $M$ could hope for would be achieved by offering the joint-surplus-maximizing quantity $q^{J S}(c)$ and charging a transfer that just ensures participation by that type, $t=\pi\left(q^{J S}(c), c\right)-$ $\pi^{A}(c)$. This observation has two immediate implication. First, for $\phi \in\left[q^{J S}\left(c_{H}\right), q^{J S}\left(c_{L}\right)\right]$ it never pays off for $M$ to serve only one type of downstream firm because, according to Proposition 9 (iii), under the optimal contract that serves both cost types each type is offered the respective joint-surplus-maximizing quantity and-with both participation constraints binding$M$ extracts all the surplus. A second implication is that even for $\phi<q^{J S}\left(c_{H}\right)$ it can never 
be optimal for $M$ to exclude the low-cost type because this type does not reject the bundle $\left(q^{J S}\left(c_{H}\right), \pi\left(q^{J S}\left(c_{H}\right), c_{H}\right)-\pi_{H}^{A}\right)$, which makes the high-cost type just break even. Thus, for $\phi<q^{J S}\left(c_{H}\right)$ the upstream supplier will always benefit from serving both types of downstream firms instead of designing a contract that excludes the low-cost type.

The remaining question is whether $M$ might benefit from excluding the high-cost type when $\phi \leq q^{J S}\left(c_{H}\right)$. Given Assumption 5, a high-cost firm always rejects the bundle $\left(q^{J S}\left(c_{L}\right)\right.$, $\left.\pi\left(q^{J S}\left(c_{L}\right), c_{L}\right)-\pi_{L}^{A}\right)$. Hence, $M$ 's profits under pricing regime $r \in\{D, U\}$ from serving only type $L$ are given by

$$
\Pi_{L}^{r}=\alpha^{r}\left[\pi\left(q^{J S}\left(c_{L}\right), c_{L}\right)-\pi_{L}^{A}-K q^{J S}\left(c_{L}\right)\right] .
$$

If, on the other hand, $M$ serves both types of downstream firms, we know that both $\left(\mathrm{IC}_{L}\right)$ and $\left(\mathrm{IR}_{H}\right)$ are binding under both pricing regimes for $\phi \leq q^{J S}\left(c_{H}\right)$. With transfers being pinned down by these constraints, the quantities offered correspond to $q_{L}^{r}\left(\alpha^{r}\right)=q^{J S}\left(c_{L}\right)$ and $q_{H}^{r}\left(\alpha^{r}\right)$ as identified in Proposition 9. Thus, $M$ 's profits from serving both types of downstream firms under pricing regime $r$ is

$$
\begin{aligned}
\Pi_{L H}^{r}=\alpha^{r}\left\{\pi\left(q^{J S}\left(c_{L}\right), c_{L}\right)-\left(c_{H}-c_{L}\right)\right. & \left.q_{H}^{r}\left(\alpha^{r}\right)-\pi_{H}^{A}-K q^{J S}\left(c_{L}\right)\right\} \\
& +\delta^{r}\left\{\pi\left(q_{H}^{r}\left(\alpha^{r}\right), c_{H}\right)-\pi_{H}^{A}-K q_{H}^{r}\left(\alpha^{r}\right)\right\} .
\end{aligned}
$$

Comparison of (B.45) and (B.46) reveals that $M$ prefers to serve only the low-cost type under pricing regime $r \in\{D, U\}$ if

$$
\alpha^{r}\left(c_{H}-c_{L}\right)\left(q_{H}^{r}\left(\alpha^{r}\right)-\phi\right)>\delta^{r}\left[\pi\left(q_{H}^{r}\left(\alpha^{r}\right), c_{H}\right)-\pi_{H}^{A}-K q_{H}^{r}\left(\alpha^{r}\right)\right] .
$$

Since $\pi\left(q_{H}, c_{H}\right)-K q_{H}$ is strictly increasing in $q_{H}$ on $\left[0, q^{J S}\left(c_{H}\right)\right)$, under Assumption 4 there exists a unique quantity between 0 and $q^{J S}\left(c_{H}\right)$ at which the right-hand side (RHS) of (B.47) equals zero. Let this quantity-threshold be denoted by $\tilde{\phi}$. Formally, $\tilde{\phi}$ is implicitly defined by

$$
\pi\left(\tilde{\phi}, c_{H}\right)-\pi_{H}^{A}-K \tilde{\phi} \equiv 0
$$

As we prove below, for $\phi \in\left[\tilde{\phi}, q^{J S}\left(c_{H}\right)\right]$ it never pays off for $M$ to exclude the high-cost downstream firm. With $\phi$ being relatively large, a low-cost downstream firm benefits by far more from procuring the input from the fringe than a high-cost downstream firm. Thus, the rents the manufacturer can extract when contracting with a low-cost type are relatively low. This in turn implies that cutting back on information rents paid to a low-cost type is less important but contracting with a high-cost type is not that unimportant. Hence, it is optimal always to contract with a high-cost downstream firm. For $\phi \in[0, \tilde{\phi})$, on the other hand, we are closer to the standard case without a fringe supply. While $M$ serves both types of downstream firms when the probability of facing a high-cost type is high, once $\alpha^{r}$ exceeds a certain threshold, $M$ considers it profitable to serve only the low-cost type. To characterize this threshold formally, fix some $\phi \in[0, \tilde{\phi})$ and consider values of $\alpha^{r} \in\left(0, \tilde{\alpha}^{r}\right]$, where $\tilde{\alpha}^{r}$ is implicitly defined by $\hat{q}^{r}\left(\tilde{\alpha}^{r}\right)=\tilde{\phi}$. Application of the envelope theorem yields

$$
\frac{d\left(\Pi_{L}^{r}-\Pi_{L H}^{r}\right)}{d \alpha^{r}}=\left(c_{H}-c_{L}\right)\left(q_{H}^{r}\left(\alpha^{r}\right)-\phi\right)+\left[\pi\left(q_{H}^{r}\left(\alpha^{r}\right), c_{H}\right)-\pi_{H}^{A}-K q_{H}^{r}\left(\alpha^{r}\right)\right]>0,
$$


where the inequality follows from the definition of $\tilde{\phi}$ in (B.48) and $\hat{q}^{r}\left(\alpha^{r}\right) \geq \tilde{\phi}$ for $\alpha^{r} \in\left(0, \tilde{\alpha}^{r}\right]$. Since $\Pi_{L}-\left.\Pi_{L H}^{r}\right|_{\alpha^{r}=0}<0$ and $\Pi_{L}-\left.\Pi_{L H}^{r}\right|_{\alpha^{r}=\tilde{\alpha}^{r}}>0$, by the intermediate value theorem we know that for any $\phi \in[0, \tilde{\phi})$ there exists a unique value $\tilde{\alpha}^{r}(\phi) \in\left(0, \tilde{\alpha}^{r}\right)$ such that

$$
\Pi_{L}^{r}-\left.\Pi_{L H}^{r}\right|_{\alpha^{r}=\alpha^{r}(\phi)} \equiv 0
$$

which yields the desired characterization of the threshold.

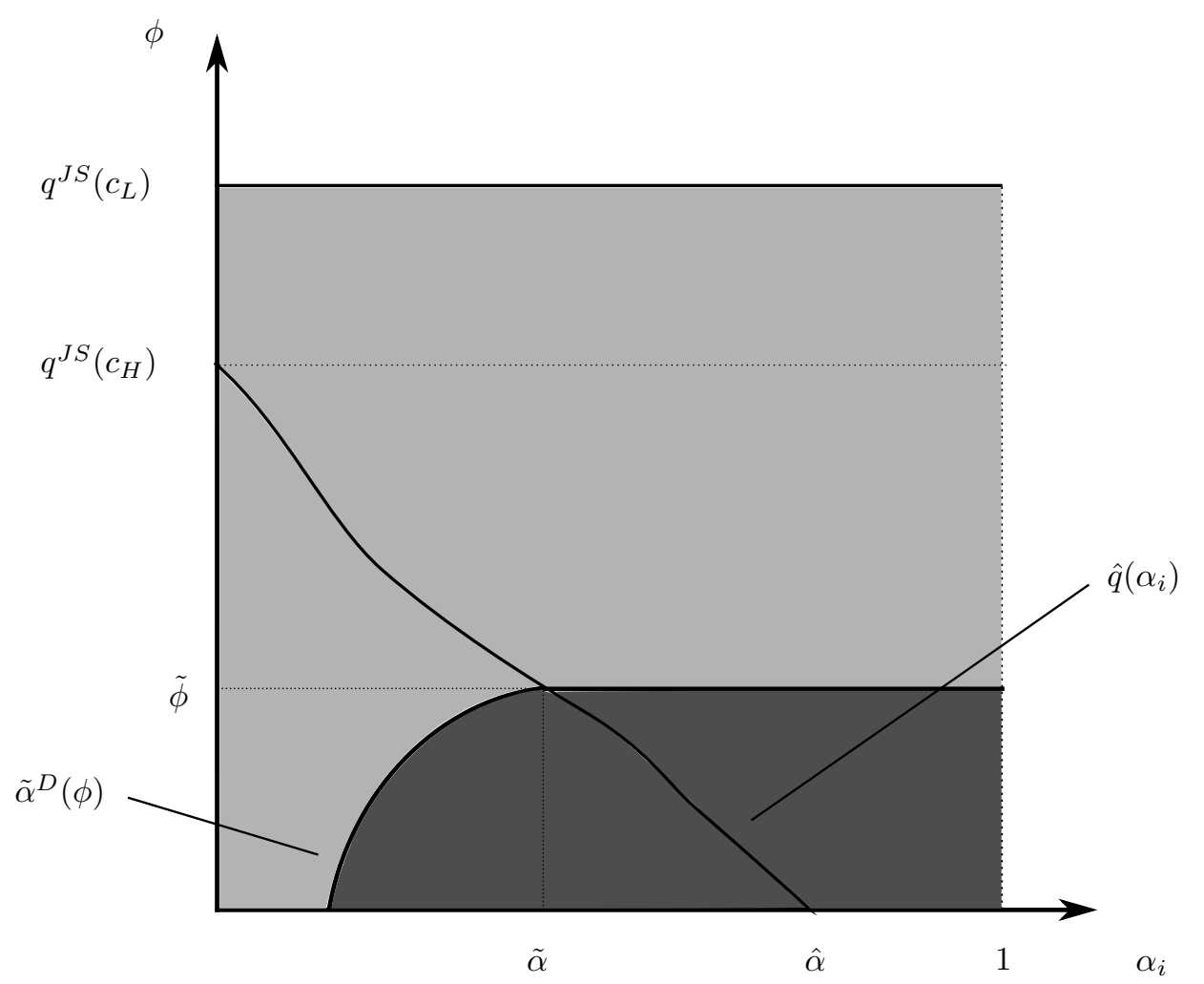

Figure 4: $M$ 's decision which types to serve

We summarize these observations in the following lemma, which is illustrated for a discriminatory pricing regime in Figure 4. In the light-gray shaded area both types of downstream firms are served, whereas in the dark-gray shaded area the high-cost type is excluded. ${ }^{29}$ In consequence, all the statements in the main text refer to the light-gray shaded area.

Lemma 7 Suppose Assumptions 4 and 5 hold. Under either pricing regime, the low-cost type is never excluded. Under pricing regime $r \in\{D, U\}$, the upstream supplier does not exclude the high-cost type if (i) $\phi \in\left[\tilde{\phi}, q^{J S}\left(c_{H}\right)\right]$, or (ii) $\phi \in[0, \tilde{\phi})$ and $\alpha^{r} \leq \tilde{\alpha}^{r}(\phi)$.

\section{Proof:}

We first prove Part (i). First, consider the case $\phi \in\left[\tilde{\phi}, q^{J S}\left(c_{H}\right)\right]$. Under pricing regime $r \in$ $\{D, U\}$, according to Proposition 9 (ii), for $\alpha^{r} \geq \alpha^{r}(\phi)$ the optimal quantity to offer when serving the high-cost type is $q_{H}^{r}\left(\alpha^{r}\right)=\phi$. In consequence, the left-hand side (LHS) of (B.47)

\footnotetext{
${ }^{29}$ As becomes obvious from (B.47), the threshold $\tilde{\alpha}^{r}(\phi)$ depends on both $\pi_{L}^{A}$ and $\pi_{H}^{A}$. In order to depict the locus of this threshold in the $\left(\alpha^{r}, \phi\right)$-space, in Figure 4 it is implicitly assumed that variations in $\phi$ are due to changes of either $\pi_{L}^{A}$ or $\pi_{H}^{A}$.
} 
equals zero, whereas the RHS is (at least weakly) positive, i.e., $M$ does not exclude the highcost type. If $\alpha^{r}<\alpha^{r}(\phi)$, then-according to Proposition 9 (i) - the optimal quantity to offer when serving a high-cost downstream firm is $q_{H}^{r}\left(\alpha^{r}\right)=\hat{q}^{r}\left(\alpha^{r}\right) \geq \phi$. To see that $M$ prefers to serve both types of downstream firms in this case as well, suppose that-while leaving the quantity to a low-cost firm unchanged $-M$ could offer $q_{H}=\phi$ to a high-cost downstream firm (instead of $\left.\hat{q}^{r}\left(\alpha^{r}\right)\right)$ together with tariffs chosen such that $\left(\mathrm{IR}_{H}^{A}\right)$ and $\left(\mathrm{IC}_{L}\right)$ bind. Since $q_{H}=\phi$, $\left(\mathrm{IR}_{L}^{A}\right)$ is satisfied with equality. With this contractual menu, the LHS of (B.47) obviously equals zero, whereas the RHS is (at least weakly) positive since $\phi \geq \tilde{\phi}$, i.e., $M$ prefers serving both types of downstream firms with this alternative allocation over serving only the low-cost type. Clearly, M's profits under the optimal contractual menu for serving both typs of downstream firms as identified in Proposition 9 (i) cannot be lower than profits under this altered allocation. In summary, under pricing regime $r \in\{D, U\}$, for $\phi \in\left[\tilde{\phi}, q^{J S}\left(c_{H}\right)\right]$ we have $\Pi_{L}^{r} \geq \Pi_{L H}^{r}$ irrespective of $\alpha^{r}$, i.e., $M$ will always serve both types of downstream firms.

Regarding part (ii) it remains to show that $M$ prefers to serve only the low-cost type for $\phi<\tilde{\phi}$ and $\alpha^{r}>\tilde{\alpha}^{r}$. If $\alpha^{r} \in\left(\tilde{\alpha}^{r}, \alpha^{r}(\phi)\right)$, then $\phi<\hat{q}^{r}\left(\alpha^{r}\right)<\tilde{\phi}$, which implies that the LHS of (B.47) is strictly positive whereas the RHS of (B.47) is strictly negative, i.e., $M$ prefers to serve only the low-cost type of downstream firm. If $\alpha^{r} \geq \alpha^{r}(\phi)$, then $q_{H}^{r}\left(\alpha^{r}\right)=\phi$. Since $\phi<\tilde{\phi}$, the left-hand side (LHS) of (B.47) equals zero, whereas the RHS is strictly negative. Thus, $M$ prefers to exclude the high-cost type in this case as well, which establishes the desired result.

Note that the upstream firm's motive for not serving the high-cost type changes as $\alpha^{r}$ increases: For $\alpha^{r}$ only slightly above the threshold $\alpha^{r}(\phi)$ the $\left(\mathrm{IR}_{L}^{A}\right)$ constraint is slack under the optimal contract when serving both firms, so $M$ 's incentive for excluding the high-cost type is rooted in the desire to cut back on the information rent paid to the low-cost type. For relatively high values of $\alpha^{r}$, on the other hand, $\left(\mathrm{IR}_{L}^{A}\right)$ is binding under the optimal contract when serving both firms; here, exclusion of the high-cost type is rooted in $M$ 's desire to avoid making losses from serving this type. 